\title{
MACROECONOMIC OUTCOMES AND COVID-19:
} A PROGRESS REPORT

\author{
Jesús Fernández-Villaverde \\ Charles I. Jones \\ Working Paper 28004 \\ http://www.nber.org/papers/w28004
NATIONAL BUREAU OF ECONOMIC RESEARCH
1050 Massachusetts Avenue
Cambridge, MA 02138
October 2020

We are grateful to Andy Atkeson and Jim Stock for many helpful comments and discussions. The views expressed herein are those of the authors and do not necessarily reflect the views of the National Bureau of Economic Research.

NBER working papers are circulated for discussion and comment purposes. They have not been peer-reviewed or been subject to the review by the NBER Board of Directors that accompanies official NBER publications.

(C) 2020 by Jesús Fernández-Villaverde and Charles I. Jones. All rights reserved. Short sections of text, not to exceed two paragraphs, may be quoted without explicit permission provided that full credit, including $\odot$ notice, is given to the source. 
Macroeconomic Outcomes and COVID-19: A Progress Report

Jesús Fernández-Villaverde and Charles I. Jones

NBER Working Paper No. 28004

October 2020

JEL No. E10,E32

\begin{abstract}
$\underline{\text { ABSTRACT }}$
This paper combines data on GDP, unemployment, and Google's COVID-19 Community Mobility Reports with data on deaths from COVID-19 to study the macroeconomic outcomes of the pandemic. We present results from an international perspective using data at the country level as well as results for individual U.S. states and key cities throughout the world. The data from these different levels of geographic aggregation offer a remarkably similar view of the pandemic despite the substantial heterogeneity in outcomes. Countries like Korea, Japan, Germany, and Norway and cities such as Tokyo and Seoul have comparatively few deaths and low macroeconomic losses. At the other extreme, New York City, Lombardy, the United Kingdom, and Madrid have many deaths and large macroeconomic losses. There are fewer locations that seem to succeed on one dimension but suffer on the other, but these include California and Sweden. The variety of cases potentially offers useful policy lessons regarding how to use nonpharmaceutical interventions to support good economic and health outcomes.
\end{abstract}

Jesús Fernández-Villaverde

Department of Economics

University of Pennsylvania

The Ronald O. Perelman Center

for Political Science and Economics

133 South 36th Street Suite 150

Philadelphia, PA 19104

and CEPR

and also NBER

jesusfv@econ.upenn.edu

Charles I. Jones

Graduate School of Business

Stanford University

655 Knight Way

Stanford, CA 94305-4800

and NBER

chad.jones@stanford.edu 


\section{Introduction}

This paper combines data on GDP, unemployment, and Google's COVID-19 Community Mobility Reports with data on deaths from COVID-19 to study the macroeconomic outcomes of the pandemic and suggest tentative policy lessons. We present results from an international perspective using data at the country level as well as results for individual U.S. states and key cities throughout the world.

The evidence to date can be summarized in a stylized way by Figure 1. On the horizontal axis is the number of deaths (per million population) from COVID-19. The vertical axis shows a cumulative measure of the macroeconomic losses apart from the value of the loss in life; for simplicity, here we call this the "GDP loss." Throughout the paper, we will show data for various countries, U.S. states, and global cities to fill in this graph quantitatively. We will also show the dynamics of how countries traverse through this space over time. For now, though, we summarize in a stylized way our main findings.

One can divide the graph into four quadrants, based on many versus few deaths from COVID-19 and on large versus small losses in GDP. Our first significant finding is that there are communities in all four quadrants.

In the lower-left corner of the diagram - the quadrant with the best outcomes are Germany, Norway, China, Japan, South Korea, and Taiwan as well as U.S. states such as Kentucky, Montana, and Idaho. Some combination of good luck and good policy means that these locations have experienced comparatively few COVID deaths as a fraction of their populations while simultaneously keeping economic activity losses relatively low.

In the opposite quadrant — the one with the worst outcomes - New York City, Lombardy, the United Kingdom, and Madrid are emblematic of places that have had comparatively high death rates and large macroeconomic losses. Some combination of bad luck and policy mistakes is likely responsible for the poor performance on both dimensions. These locations were unlucky to be hit relatively early in the pandemic, perhaps by a strain of the virus that was more contagious than the one prevalent in other locations. Being hit early also meant that communities often did not take appropriate measures in nursing homes and care facilities to ensure that the most susceptible were adequately protected and that the medical protocols at hospitals were less well- 
Figure 1: Summary of the Trade-off Evidence

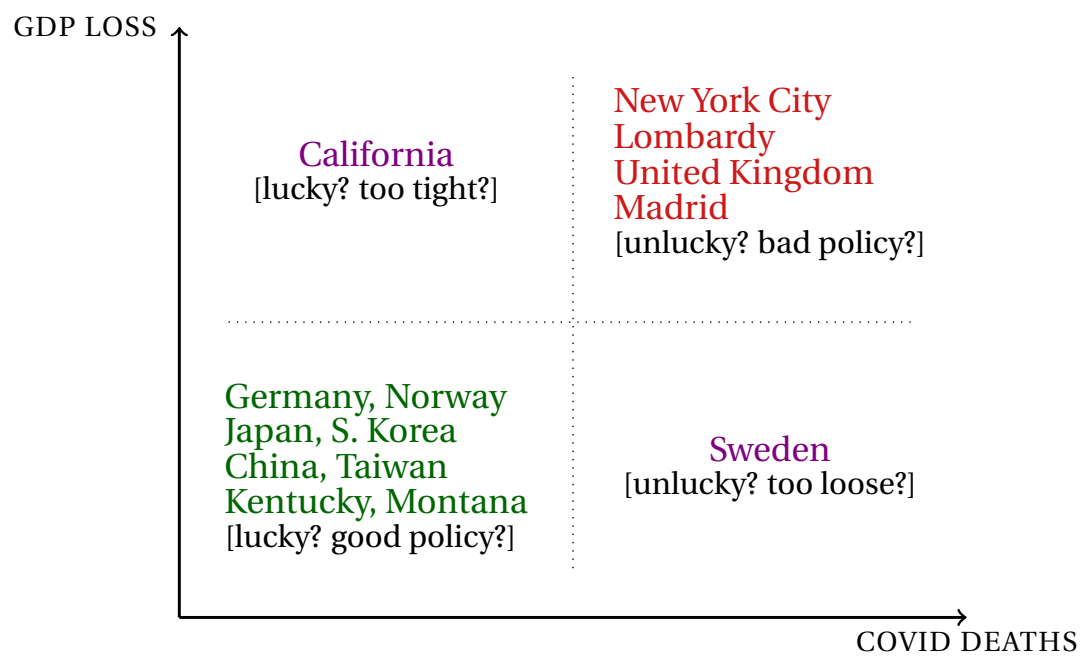

developed.

The other two quadrants of the chart stand out in interesting ways, having good performance on one dimension and poor performance on the other. Compared to New York, Lombardy, Madrid, and the U.K., Sweden and Stockholm had comparable death rates with much smaller losses in economic activity. But of course, that is not the only comparison. Relative to Norway and Germany, Sweden had many more deaths and comparable losses in economic activity. Relative to the worst outcomes in the northeast quadrant, Sweden is a success. But relative to what was possible - as illustrated by Germany and Norway — Sweden could have done better.

California, in the quadrant opposite of Sweden, also makes for a fruitful comparison. Relative to New York, California had similarly large losses in economic activity, but far fewer deaths. At the start of the summer, both states had unemployment rates on the order of 15 percent. But New York had 1700 deaths per million residents, while California had just 300. From New York's perspective, California looks enviable. On the other hand, California looks less successful when compared to Germany, Norway, Japan, and South Korea. These places had similarly low deaths but much smaller losses in economic activity. Once again, relative to what was possible - as illustrated by the best-performing places in the world - California could have done better.

One essential caveat in this analysis is that the pandemic continues. This chart and 
the graphs below that it is based on may very well look quite different six months from now. One of the most critical dimensions of luck is related to whether a location was hit early by the pandemic or has not - yet? — been severely affected. Will a vaccine or cheap, widespread testing end the pandemic before these places are impacted?

Still, with this caveat in mind, probably the most important lesson of the paper is that there many observations in the lower-left quadrant of the graph: good outcomes on both the GDP and COVID mortality outcomes are possible.

Good policy can support better outcomes. We read our findings as suggestive (although not conclusive) evidence of the importance of good policies. Places like China, Germany, Japan, Norway, South Korea, and Taiwan are heterogeneous along various dimensions. The set includes large, dense cities such as Seoul and Tokyo. The set contains nations that were forewarned by experiences with SARS and MERS and countries like Germany and Norway that did not have this direct experience. There are places that were hit early, like China and South Korea, and places that were hit later, like Germany and Norway.

At the same time, our paper does not highlight precisely what these countries did to get these good outcomes. Such a task is next to impossible using aggregate data and requires the use of the micro data analysis that exploits local variation (as in the many papers we will cite below).

However, our findings suggest where to look for these more in-depth lessons. For example, China, Taiwan, and South Korea focused early on non-pharmaceutical interventions (NPIs) such as widespread use of masks, protection of the elderly, better indoor ventilation, limited indoor contact, and widespread testing and quarantine. In the case of Taiwan, C. Jason Wang (2020) report how the aggressive use of IT and big data supported the successful application of NPIs, a model copied to a large extent by China and South Korea.

Conversely, countries such as Spain and Italy, which suffered a harsh first wave but did not improve enough in terms of using analytics to track the epidemic, are again on a tight spot regarding cases, hospital occupancy, and deaths. As we move through the second wage of COVID-19 cases in the U.S. and Western Europe, the lessons regarding NPIs can improve both economic activity and death outcomes. 
Government-mandated policy versus self-protecting behavior. By good policy, we do not just mean government-mandated actions, but also all self-protecting voluntary changes in private behavior (perhaps induced by government information campaigns). Think about the case of the airline industry. Flight occupancy can fall because of government-imposed mandates such as international travel quarantines but also through the widespread voluntary cancellation of travel.

A growing consensus suggests that voluntary changes have played a crucial role. For instance, Arnon, Ricco and Smetters (2020), using an integrated epidemiologicaleconometric model and county-level data, argue that the bulk of reductions in U.S. contact rates and employment came from voluntary changes in behavior. However, the authors show that government-mandated NPIs reduced COVID-19 deaths by $30 \%$ during the first three months of the pandemic.

Goolsbee and Syverson (2020) compare consumer behavior within the same commuting zones but across boundaries with different policy regimes to conclude that legal restrictions account only for 7 percentage points (p.p.) of the overall reduction of over 60 p.p. in consumer traffic. Nonetheless, the authors document that NPIs shift consumer activity across different industries (e.g., from restaurants into groceries).

Equivalent results to Arnon, Ricco and Smetters (2020) and Goolsbee and Syverson (2020) are reported using smartphone data by Gupta, Nguyen, Rojas, Raman, Lee, Bento, Simon and Wing (2020) and unemployment insurance claims and vacancy posting by Forsythe, Kahn, Lange and Wiczer (2020). ${ }^{1}$ Similar findings regarding the preponderance of voluntary changes in behavior are reported for Europe by Chen, Igan, Pierri and Presbitero (2020), South Korea by Aum, Lee and Shin (2020), and Japan by Watanabe and Yabu (2020).

At a more aggregate level, Atkeson, Kopecky and Zha (2020) highlight, using a range of epidemiological models, that a relatively small impact of government mandates is the only way to reconcile the observed data on the progression of COVID across a wide cross-section of countries with quantitative theory.

Notice that even if most of the reduction in mobility comes from voluntary decisions, we might still be far from a social optimum as agents do not fully account for the contagion externalities they create. Importantly, government information surely

\footnotetext{
${ }^{1}$ Couture, Dingel, Green, Handbury and Williams (2020) show that smartphone data is a reliable snapshot of social activities.
} 
plays a key role in shaping agents' beliefs about the state of the epidemic and, therefore, influences voluntary behavior.

Literature Review. Over the last few months, a gigantic literature on COVID-19 and economics has appeared. It is beyond our scope to review such literature, which touches on multiple questions, from the design of optimal mitigation policies (Acemoglu, Chernozhukov, Werning and Whinston, 2020) to COVID-19's impact on gender equality (Alon, Doepke, Olmstead-Rumsey and Tertilt, 2020). Instead, we highlight three sets of papers that have explored the interaction between COVID-19, the policy responses to it, and economic outcomes.

The first set of papers has extended standard economic models to incorporate an epidemiological block. Among those, early efforts include Álvarez, Argente and Lippi (2020), Eichenbaum, Rebelo and Trabandt (2020), Glover, Heathcote, Krueger and RíosRull (2020), and Farboodi, Jarosch and Shimer (2020). In this tradition, the contributions of models with many different sectors (Baqaee and Farhi, 2020a,b; Baqaee, Farhi, Mina and Stock, 2020) are particularly interesting for the goal of merging microdata with aggregate outcomes and the design of optimal reopening policies. These models will also serve, in the future, as potential laboratories to measure the role of luck vs. policy that we discussed above.

A second set of papers has attempted to measure the effects of lockdown policies. The results using Chinese data in Fang, Wang and Yang (2020) indicate that early and aggressive lockdowns can have large effects in controlling the epidemic and findings using German (Mitze, Kosfeld, Rode and Wälde, 2020) and Canadian data (Karaivanov, Lu, Shigeoka, Chen and Pamplona, 2020) point out to the effectiveness of face masks in slowing contagion growth. Amuedo-Dorantes, Kaushal and Muchow (2020) study U.S. county-level data to argue that NPIs interventions have a significant impact on mortality and infections.

A subset of these papers has dealt with Sweden, a country that implemented a much more lenient lockdown policy than its Northern European neighbors. Among the papers that offer a more favorable assessment of the Swedish experience, Juranek, Paetzold, Winner and Zoutman (2020) have gathered administrative data on weekly new unemployment and furlough spells from all 56 regions of Sweden, Denmark, Fin- 
land, and Norway. Using an event-study difference-in-differences design, the authors conclude that Sweden's lighter approach to lockdowns saved between 9,000 and 32,000 seasonally and regionally adjusted cumulative unemployment/furlough spells per million population by week 21 of the pandemic. If we compare, for example, Sweden with Norway, these numbers suggest a crude trade-off (without controlling for any other variable) of around 61 jobs lost per life saved. ${ }^{2}$ On the negative side, Born, Dietrich and Müller (2020) and Cho (2020), using a synthetic control approach, find that stricter lockdown measures would have been associated with lower excess mortality in Sweden by between a quarter and a third.

The third set of papers has studied how to monitor the economy in real time (Cajner, Crane, Decker, Grigsby, Hamins-Puertolas, Hurst, Kurz and Yildirmaz, 2020; Stock, 2020), how the sectoral composition of each country matters for the reported output and employment losses (Gottlieb, Grobovsek, Poschke and Saltiel, 2020), and the impact of concrete policy measures. Among the latter, Chetty, Friedman, Hendren, Stepner and Team (2020) argue that stimulating aggregate demand or providing liquidity to businesses might have limited effects when the main constraint is the unwillingness of households to consume due to health risks and that social insurance programs can be a superior mitigation tool. Goldberg and Reed (2020) extend the analysis of current economic conditions related to COVID-19 to emerging market and developing economies.

Structure of the paper. In the remainder of the paper, we present the detailed evidence that underlies this stylized summary. Section 2 lays out a basic framework for thinking about Figure 1. Section 3 presents evidence for countries using data on GDP from the first and second quarters of 2020 to measure the macroeconomic outcomes. It also shows evidence for U.S. states using monthly unemployment rates. Section 4 then turns to a complementary source of data on economic activity, the Google Community Mobility Reports. We show that these economic activity measures are highly correlated with GDP and unemployment rates. The Google measures have additional advantages, however. In particular, they are available for a large number of locations at varying geographic levels of aggregation, are reported at the daily frequency, and are reported

\footnotetext{
${ }^{2}$ Among many other elements, this computation does not control for the possibility that Sweden, by getting closer to herd immunity, might have saved future deaths or, conversely, that higher death rates today might have long-run scarring effects on Swedish GDP and labor market.
} 
with a lag of only just a few days, an important feature given the natural lags in NIPA reporting. We reproduce our earlier findings using the Google data and produce new charts for key cities worldwide. The city-level data is important because of concerns about aggregating to, say, the national level across regions of varying densities. Section 5 shows the dynamic version of our graphs at the monthly frequency using the Google data, so we can see how different locations are evolving. Finally, Section 6 offers some closing thoughts. 


\section{Framework}

We focus on two outcomes in this paper: the loss in economic activity, as captured by reduced GDP or increased unemployment, and the number of deaths from COVID19 per million people. ${ }^{3}$ Even with just these simple outcome measures, it is easy to illustrate the subtle interactions that occur in the pandemic.

Figure 2: Economic Policy Trade Off, Holding Health Policy and Luck Constant

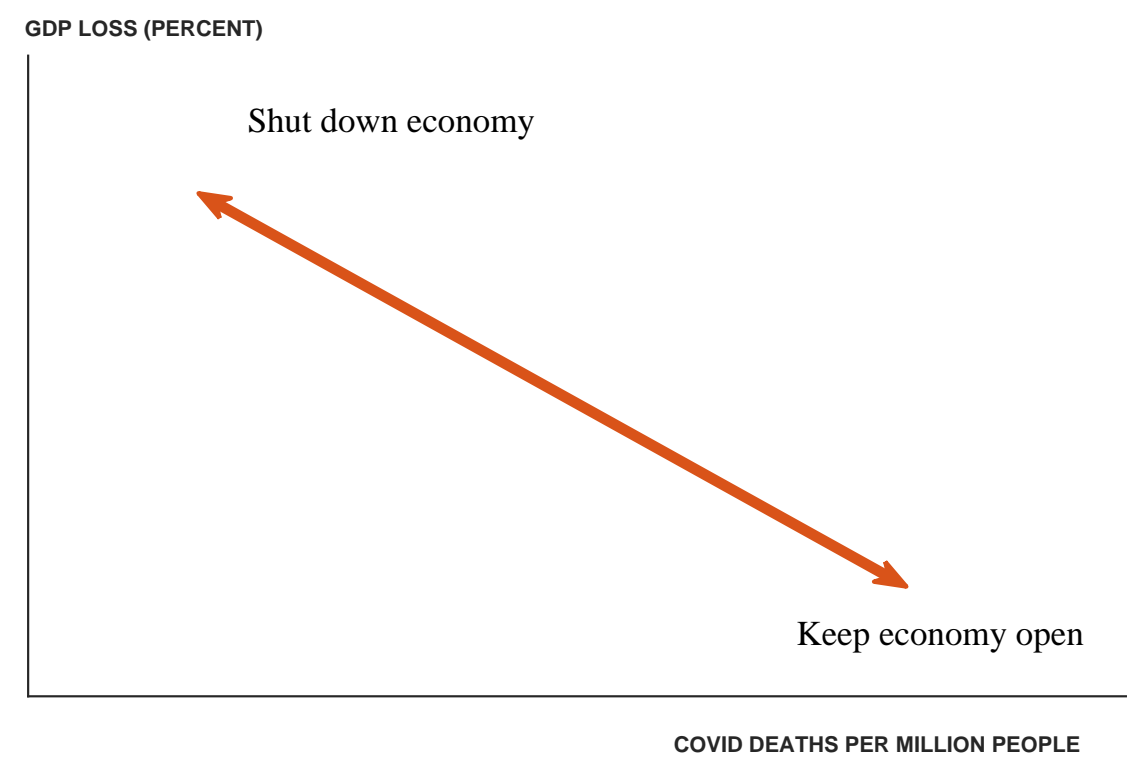

Note: Holding health policy and "luck" constant, economic policy implies a tradeoff between economic activity and deaths from COVID-19.

To begin, Figure 2 illustrates a simple tradeoff between economic activity and deaths from the pandemic. In the short term, economic policy can shut the economy down sharply, which increases the economic losses on the vertical axis but saves lives on the horizontal axis. Alternatively, policy could focus on keeping the economy active to minimize the loss in GDP at the expense of more deaths from the pandemic.

Figure 3 shows that the story is more complicated when health policy and luck are brought under consideration. There can be a positive correlation between economic losses and COVID deaths. Good NPIs - for example, widespread use of masks, better indoor ventilation, protecting nursing homes, and targeted reductions in super-

\footnotetext{
${ }^{3}$ There is a growing concern about the long-run health consequences for individuals who survived a COVID-19 infection. However, it is too early for any systematic international comparison of those longrun effects.
} 
Figure 3: Health Policy Decisions and Luck Can Shift the Trade-off

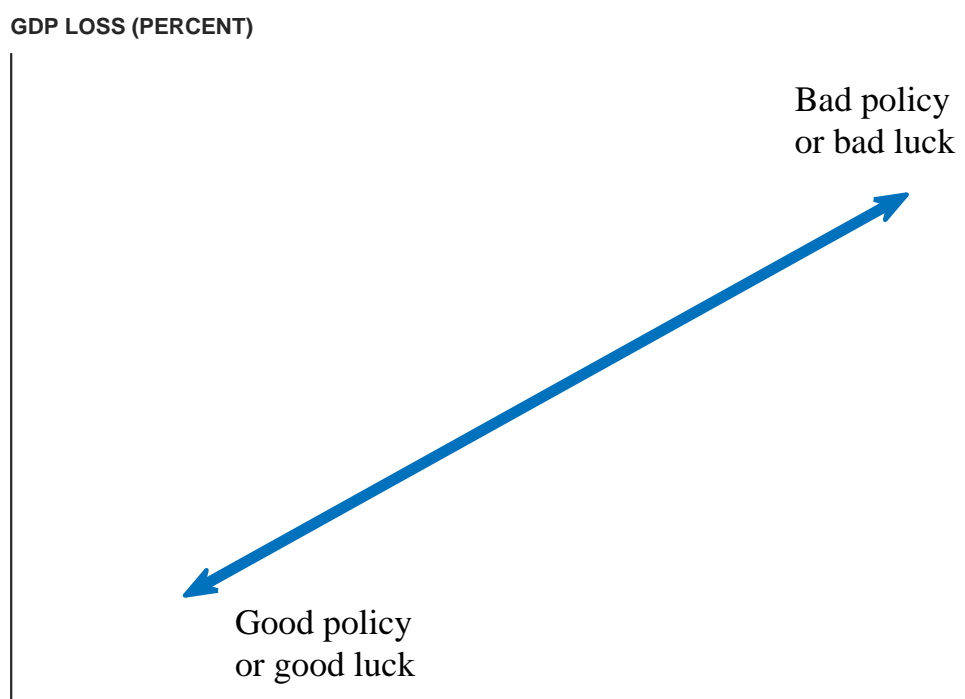

COVID DEATHS PER MILLION PEOPLE

Note: Health policy and luck can shift the tradeoff between economic activity and deaths from COVID-19.

spreader events such as choirs, bars, nightclubs, and parties - can reduce the number of deaths with a limited impact on production. Furthermore, by reducing the death rate, such policies encourage economic activity by allowing people to return safely to work and the marketplace.

Similarly, luck plays an important but not yet fully-understood role. Where does the coronavirus strike early versus late? Perhaps a country is in the lower-left corner today with low deaths and little loss in GDP, but only because it has been lucky to avoid a severe outbreak. Two months from now, things may look different. Alternatively, is a region hit by a less infectious and deadly virus strain (see our next subsection)?

Given the steep age pattern of COVID-19 mortality rates, basic demographic differences influence the trade-off between deaths and GDP losses. This is another dimension of what we can call luck. COVID-19 has a steep age and obesity gradient. Younger and less-obese countries, many of them emerging market and developing economies, have experienced much better outcomes than one would have expected (Goldberg and Reed, 2020).

To complicate matters, all of these forces play out over time, which gives rise to 
Figure 4: Economic Activity, Covid Deaths, Health Policy, and Luck

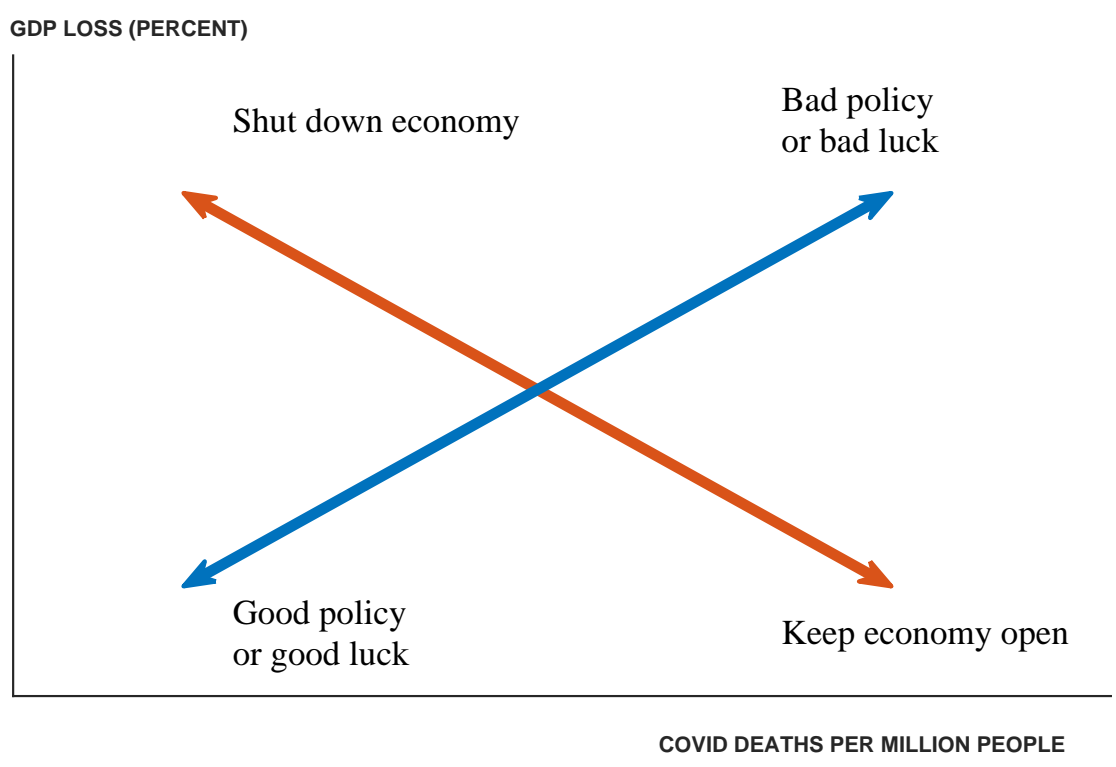

Note: Putting the two together explains why the data can be hard to interpret.

important dynamic considerations. For example, a community may keep the economy open in the short term, which may lead to a wave of deaths, and then be compelled to shut the economy down to prevent even more deaths. Two communities can end up with large economic losses, but very different mortality outcomes, because of these timing considerations. This can be thought of as being embodied in Figure 3.

Figure 4 puts these mechanisms together in a single chart. It reveals that the correlation between economic losses and COVID deaths that we see in the data is governed by a sophisticated collection of forces, both static and dynamic. When we see a cloud of data points in the empirical versions of this graph, we can think about how these various forces are playing out.

Evidence on the Role of Mutation. We have mentioned several times that a simple mechanism behind luck is the strain of the virus that attacked one location. From March to May of 2020, a SARS-CoV-2 variant carrying the Spike protein G614 that likely appeared in some moment in February replaced D614 as the dominant virus form globally (Korber et al., 2020).

While the global transition to the G614 variant is a well-established fact, its practical 
consequences are still debated. Korber et al. (2020) present experimental evidence that the G614 variant is associated with greater infectivity and clinical evidence that the new variant is linked with higher viral loads, although not with greater disease severity. Hu et al. (2020), Ozono et al. (2020), and Zhang et al. (2020) report similar findings. However, these latter results regarding greater infectivity and higher viral load are not yet the consensus among scientists (Grubaugh et al., 2020).

In other words, there is some evidence - although far from conclusive - that the pandemic's timing may have played a role in determining the quadrant where each place falls in Figure 1. If indeed the original D614 variant is less infectious, Asian countries (who were exposed more to this earlier form of the virus) faced a more straightforward trade-off between containing the epidemic and sustaining economic activity. Even within the U.S., California, likely due to its closer ties to Asia, experienced a higher prevalence of lineages of D614 at the start of the health crisis than New York, closer to Europe, and thus it had better outcomes regardless of the policies adopted. 


\section{Cumulative Deaths and Cumulative Economic Loss}

This section shows the empirical versions of the trade-off graphs for various countries and U.S. states using GDP and unemployment as measures of the economic outcomes.

\subsection{International Evidence}

We use GDP data from the OECD $(2020)^{4}$ and death data from Johns Hopkins University CSSE (2020) to study the international evidence on COVID-19 deaths and GDP. Figure 5 plots the COVID-19 deaths per million population as of October 9 against the loss in GDP. "GDP Loss" is the cumulative loss in GDP since the start of 2020 (we currently have data from Q1 and Q2) and is annualized. For example, a value of 6 means that the loss since the start of 2020 is equivalent to a six percent loss in annual GDP.

Figure 5: International Covid Deaths and Lost GDP

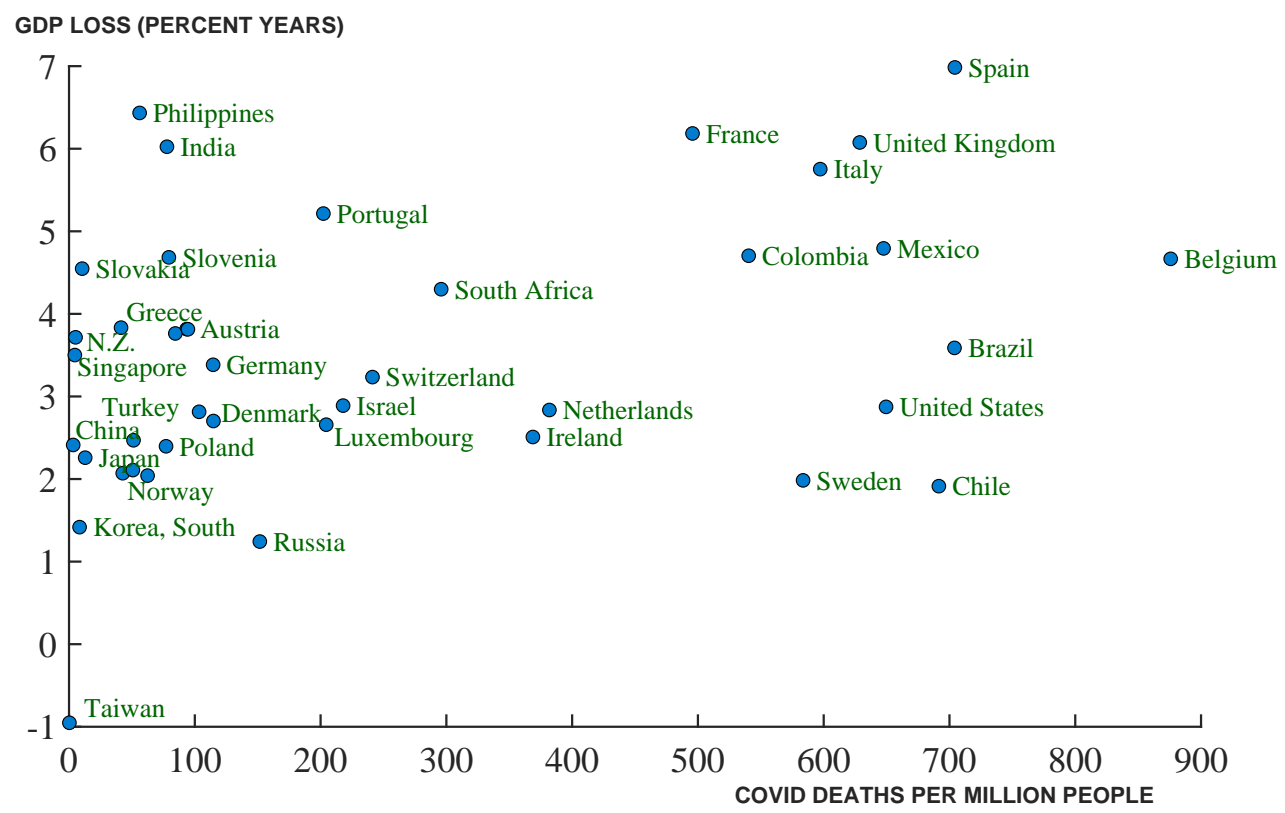

Note: "GDP Loss" is the cumulative loss in GDP since the start of 2020 and is annualized. For example, a value of 6 means that the loss since the start of 2020 is as if the economy lost six percent of its annual GDP.

Before discussing our findings, some warnings are appropriate. First, we only have observations up to 2020Q2. Second, the numbers released so far are likely to be revised

\footnotetext{
${ }^{4}$ We also use data from various national statistical agencies for several countries not in the OECD database; see Appendix A.
} 
substantially. Even in normal times, the revisions of GDP early releases are considerable (Aruoba, 2008). The difficulties in data collection during the pandemic suggest that the revisions for 2020 are bound to be even larger. ${ }^{5}$ Third, GDP is only an imperfect measure of economic activity. There are reasons to believe that those imperfections are even more acute nowadays.

For instance, consider government consumption. This item is measured by the sum of employee compensation, consumption of fixed capital, and intermediate goods and services purchased. Many government services, from the local DMV to public schools, were not offered (or only offered under a very limited schedule) during the lockdowns. However, most government employees were still paid (furloughs were rare in OECD countries), and the consumption of fixed capital is imputed according to fixed depreciation tables. Thus, except for some reduction of intermediate goods and services purchased, government consumption remained unchanged from the perspective of GDP. Indeed, in the U.S., real government consumption increased 0.6 percent in 2020Q2 while GDP dropped 9.1 percent. While part of the increase can be attributed to the fiscal stimulus and the fight against COVID-19, a substantial part of government consumption operated well below normal levels during that quarter with little impact on measured GDP.

With these considerations in mind, Figure 5 suggests that there has not been a simple tradeoff between deaths and GDP. Rather, countries can be seen to fall into several groups.

First, we have countries with low deaths and moderate GDP losses: Taiwan (with positive GDP growth!), Korea, Indonesia, Norway, Japan, China, Poland, and Germany. Such countries illustrate an important lesson from the crisis: it was possible to emerge with relatively good performance on both dimensions. Importantly, this group is heterogeneous. It includes countries in both Asia and Europe. It includes countries with large, densely populated cities. And it includes countries that are globally highly con-

\footnotetext{
${ }^{5}$ Recall, for example, the note on the Coronavirus (COVID-19) Impact on June 2020 Establishment and Household Survey Data: “The household survey is generally collected through in-person and telephone interviews, but personal interviews were not conducted for the safety of interviewers and respondents. The household survey response rate, at 65 percent, was about 18 percentage points lower than in months prior to the pandemic." https://www.bls.gov/cps/employment-situation-covid19-faq-june-2020.pdf. A similar issue relates to the state unemployment rates that we will use later. These rates are a combination of survey measurement on small state-level samples and a pooled time series model run by the BLS. During the last months, we have seen large revisions in these rates.
} 
nected to the rest of the world, including Germany and China, the two major export powerhouses of the world economy. Other countries nearby in the diagram include Poland, Greece, and Estonia.

Presumably, both good policy and good luck play important roles here. For example, Greece, a dense country with a poor track record in terms of economic governance and a public health system starved of resources after a decade of budget cuts, has performed so far surprisingly well. Greece's government approved restrictive measures when the number of cases was minimal and directed a well-coordinated health strategy. At the same time, Greece is less well connected with the rest of the European Union and has a fragmented geography, which has slowed down the virus's spread. Uncovering the explanation for Greece's success could yield important lessons.

Next, in the graph's upper-right part, we have countries with high death rates and large GDP losses: France, Spain, Italy, the U.K., and Belgium. Some combination of bad luck and imperfect policy led these regions to suffer on both dimensions during the pandemic. The United Kingdom, as an example, has suffered from more than 600 deaths per million people and already lost the equivalent of 6 percent of a year's GDP. Also, high COVID-19 incidence might trigger nonlinear effects on mortality. There is evidence that the Italian and Spanish health systems were overwhelmed in March 2020, leading to many deaths that could have been avoided. Ciminelli and Garcia-Mandicó (2020) show that mortality in the Italian municipalities that were far from an ICU was up to 50 percent higher, which they argue was due to the congestion of the emergency care system during those crucial weeks.

A few countries in Figure 5 are harder to classify. India and the Philippines have experienced a considerable reduction in GDP, but comparatively few deaths per million people. As we will see later, however, the situation in India is still very much evolving. The United States and Sweden also stand out, with many COVID-19 deaths but smaller reductions in GDP than France, Italy, or Spain. As with India, however, the dynamic graphs we show later suggests that the position of the United States is still in flux.

The case of Sweden is particularly interesting because its government defied the consensus among other advanced economies and imposed much milder restrictions and explicitly aimed for herd immunity. Compared to the U.K., Spain, or Italy, Sweden looks like a success story: it has a comparable number of deaths when normalized by 
population, but a significantly smaller loss in GDP. The shutdown in the U.K., Spain, and Italy has already cost these economies the equivalent of 6 percent of their annual GDP, while the loss in Sweden has been just 2 percent of GDP.

On the other hand, with an alternative comparison, Sweden looks worse. In terms of deaths, Sweden has had around 575 deaths per million population vs. 50 in Norway, 60 in Finland, 115 in Denmark, and 115 in Germany. The other Nordic countries are a natural comparison group in terms of socio-economic conditions, although differences in population distribution and mobility within this group should not be underestimated. Regarding economic outcomes, Norway and Sweden both report GDP losses of around 2 percent, while Denmark, Germany, and Austria are only slightly larger.

In the case of the U.S., the current high levels of infection and deaths mean that the country is still moving to the right in Figure 5. The recent rise in cases in Western Europe is at such an early stage that it is impossible to gauge whether these countries will also witness significant levels of additional deaths.

Finally, notice that Figure 5 correlates COVID-19 deaths and GDP losses without controlling for additional variables (initial income per capita, industrial sectoral composition, density, demographics, etc.). We checked for the effects of possible controls, and we did not find any systematic pattern worth reporting.

\subsection{U.S. States and Unemployment}

We now consider economic outcomes and deaths from COVID-19 across U.S. states. In this case, our measure of economic activity is the unemployment rate. Figure 6 shows the unemployment rate for U.S. states from August 2020 plotted against the number of deaths per million people as of October 9.

The heterogeneity in both the unemployment rate and in COVID deaths is remarkable. States like New York, Massachusetts, and New Jersey have more than 1200 deaths per million residents as well as unemployment rates that even after several months of recovery exceed 10 percent in August. In contrast, states like Utah, Idaho, Montana, and Wyoming have very few deaths and unemployment rates of between 4 and 7 percent.

Figure 7 cumulates the unemployment losses since February to create a more informative measure of the macroeconomic cost of the pandemic. In particular, we measure "cumulative excess unemployment" by summing the deviations from each state's 
Figure 6: U.S. States: Covid Deaths and the Unemployment Rate

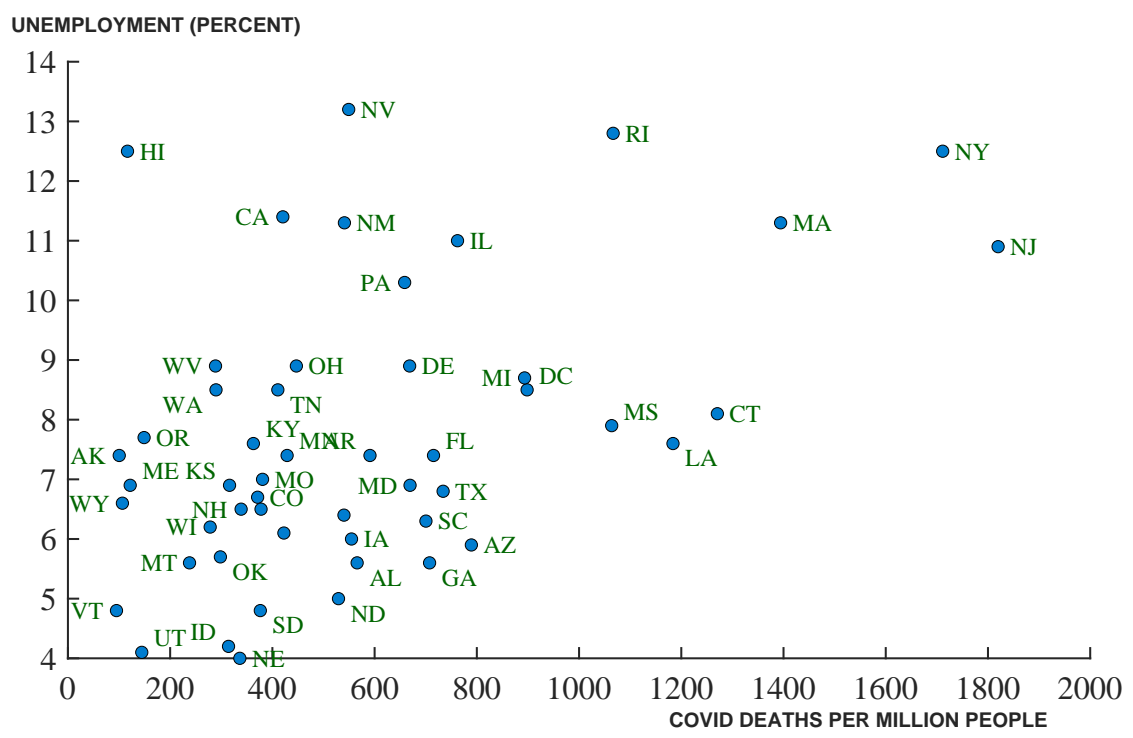

Note: The unemployment rate is from August 2020.

Figure 7: U.S. States: Covid Deaths and Cumulative Excess Unemployment

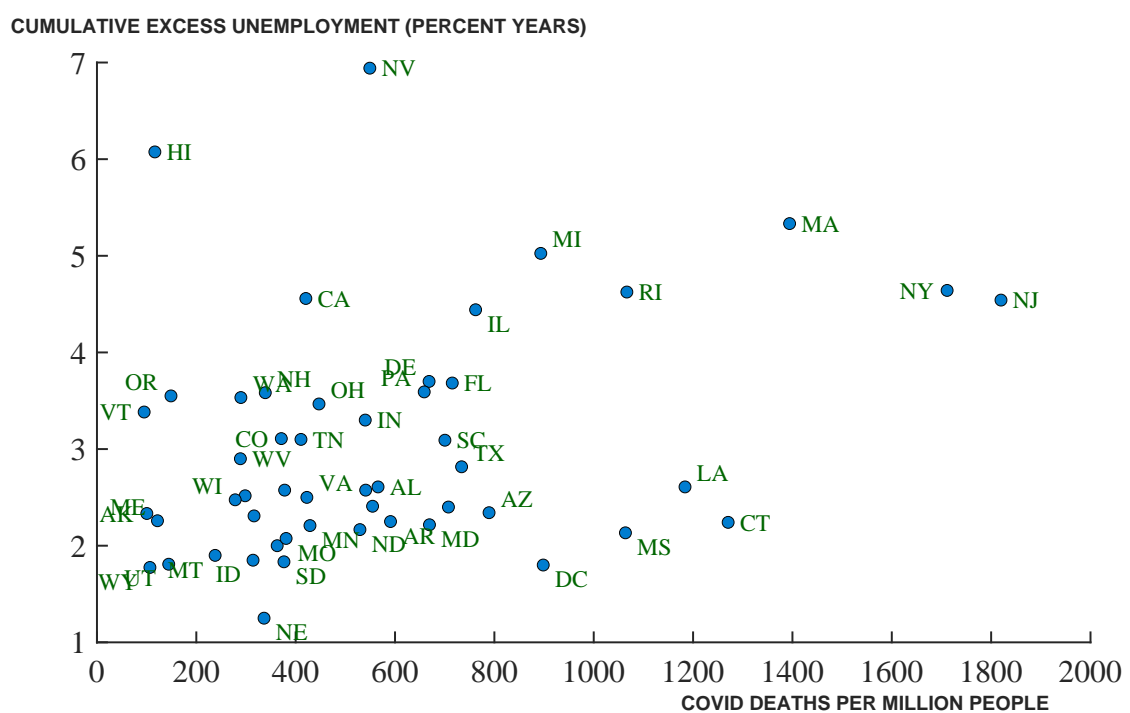

Note: Cumulative excess unemployment adds the deviations from each state's February 2020 rate for each month and then divides by 12 to annualize. In other words the loss to date is equivalent to having the unemployment rate be higher by $x$ percent for an entire year. 
February 2020 rate for each month and then dividing by 12 to annualize. In other words, a number like 6 in the graph implies that the loss to date is equivalent to having the unemployment rate be elevated by 6 percentage points for an entire year.

In this figure, it is interesting to compare New York, California, and Washington DC. Both New York and California have had large declines in economic activity, the equivalent of having the unemployment rate be elevated by about 5 percentage points for an entire year. However, the number of deaths is very different in these two states. New York has around 1700 deaths per million people, while California has around 400 as of October 9. What combination of luck and policy explains this outcome? Both states got hit relatively early by the coronavirus. Was California lucky to get a strain from Asia that was less contagious and less deadly while New York got a strain from Europe that was more contagious and more deadly? Or did the policy differences between New York and California have enormous effects?

When compared to New York, California looks like a resounding success. On the other hand, one can also compare California to states like Washington and Minnesota, not to mention Kentucky and Nebraska. All of these other states had similar death rates but smaller employment losses. Did California shut down too much? Or were Nebraska and Minnesota lucky? Or did population density play an imporant role?

Finally, Washington DC stands out as a state with relatively small employment losses - equivalent to an unemployment rate that is elevated by just 2 percentage points for a year - but substantial deaths. DC looks somewhat like Sweden in this graph, but when we turn to the Google activity data below, the story will be a bit different: the prevalence of government jobs with stable employment may have limited the rise in the DC unemployment rate.

\subsection{International Comparisons of Unemployment}

Given our previous analysis, it would seem natural to compare the evolution of unemployment rates among the advanced economies. However, such a comparison is not especially informative in gauging the effects of COVID-19.

Many countries have passed generous government programs to induce firms to keep workers on the payroll even during lockdowns, count workers on furloughs with reduced pay as being employed, or classify workers who lost their jobs as out of the 
labor force if they are not searching for a new job due to the "stay-at-home" orders. Furthermore, severance costs make firing workers after a relatively transitory shock unattractive: firms might end up paying more in severance packages than just keeping their workers at home with pay for a few months. That means that the measured unemployment rate in some of the most severely hit countries has only increased by a few percentage points (from 13.6\% in February 2020 to $15.6 \%$ in June 2020 in Spain) or even fallen (from $9.2 \%$ in February 2020 to $8.8 \%$ in June 2020 in Italy). ${ }^{6}$

The main exception is the United States, which features substantially different labor market regulations: unemployment jumped from 4.4\% in February 2020 to $14.7 \%$ in March 2020 but then declined to 7.9\% in September 2020.

\section{Activity from the Google Mobility Report Data}

GDP and unemployment rates are standard macroeconomic indicators that are extremely useful. However, they also suffer from some limitations related to frequency and availability. In this section, we turn to another source of evidence: the COVID19 Community Mobility Report data from Google (2020). For shorthand, we will refer to this as the "Google activity" measure. These data show how daily location activity changes over time in a large number of countries and regions. The outcomes are grouped according to several destinations: retail and recreation, grocery and pharmacy, parks, transit stations, workplaces, and residences.

The Google activity measure has several key advantages relative to GDP or unemployment. First, it is available at a daily frequency, rather than quarterly or monthly. Second, it is reported with a very short lag of just a few days. By comparison, we only have 2020Q2 GDP data for a handful of countries and our latest unemployment rate data for U.S. states is from August. Finally, the Google data is also available at a very disaggregated geographic level, allowing us to look at cities as well as states and countries. In what follows, we focus on Google activity, defined as the equally-weighted average of the "retail and entertainment" and "workplace" categories.

\footnotetext{
${ }^{6}$ Similar arguments would apply to a comparison of employment rates. The number of hours worked is reported by the OECD only at an annual frequency.
} 
Figure 8: Google Activity: International Evidence

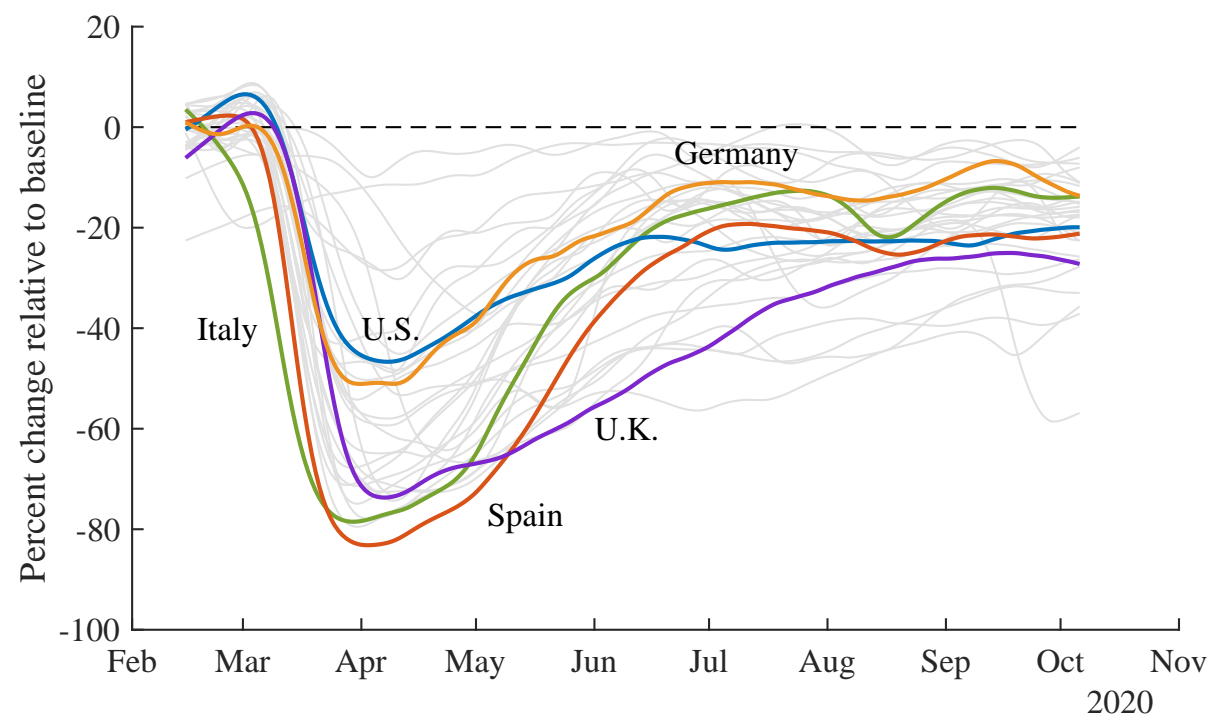

Note: Google activity is the equally-weighted average of the "retail and entertainment" and "workplace" categories. The data are smoothed with an HP filter with smoothing parameter 400.

\subsection{Google Activity over Time}

Figures 8 shows the (smoothed) Google activity data over time for a large number of countries, highlighting a few. Italy and Spain show very sharp declines in activity starting quite early compared to the declines in the U.S., the U.K., and Germany. Activity recovers somewhat in May in Italy and Spain, but only gradually in the U.K. This appears to be a case of the U.K. being slow to get the pandemic under control, suffering from more deaths as a result, and being forced to keep its economy shut down for longer.

The U.S. and Germany are also interesting, in comparison. They have somewhat similar changes in activity, but, as we've seen, very different COVID outcomes. Among the highlighted countries, Germany had the smallest loss in economic activity and the fewest deaths.

Next, consider Figure 9 which highlights the Scandinavian countries. These countries have even milder shutdowns than Germany and the United States. Sweden's shutdown is initially the mildest but by June it looks similar to Germany, Denmark, and Norway. 
Figure 9: Google Activity: Northern Europe

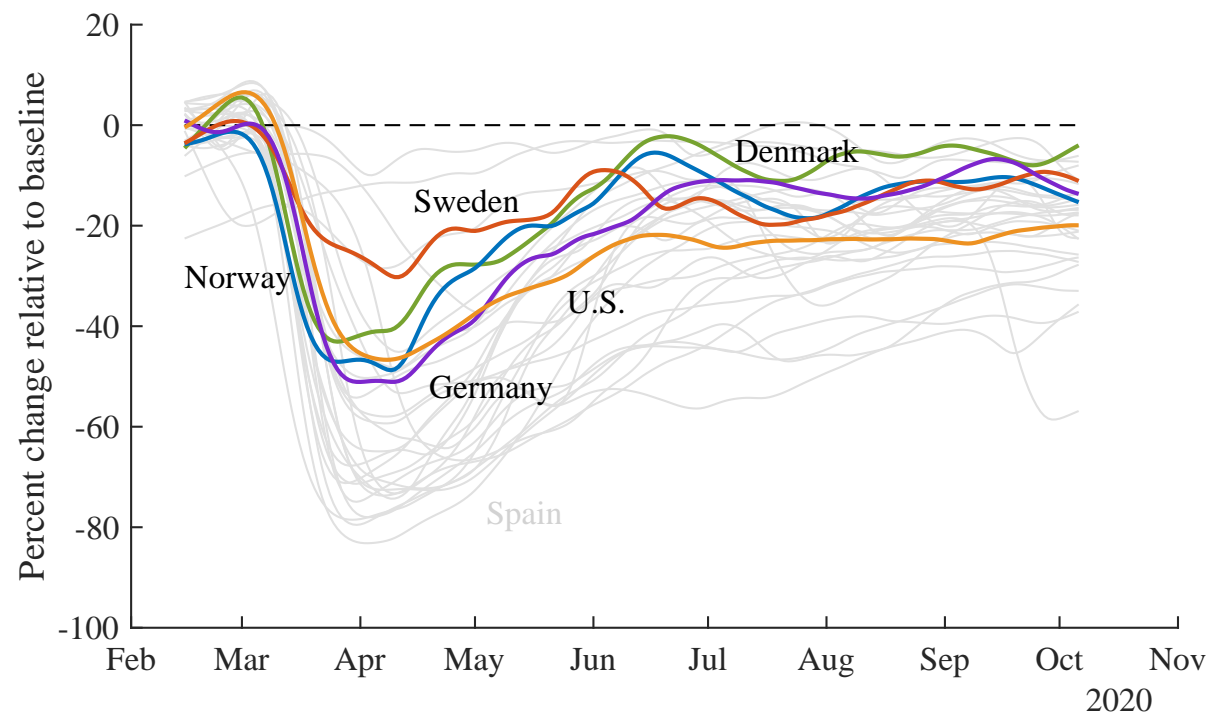

Note: Google activity is the equally-weighted average of the "retail and entertainment" and "workplace" categories. The data are smoothed with an HP filter with smoothing parameter 400.

Global Cities. Figure 10 shows the Google activity measure for 14 key international cities or regions. Lombardy and Seoul have very early shutdowns with 20 percent declines in activity by the first of March. Madrid and Paris and then New York City and finally London follow them down, with all four seeing activity down by around 80 percent as of April 1. Seoul recovers very quickly, while Tokyo sees a slow decline. Stockholm also has mild losses according to the Google activity measure.

U.S. States. Figure 11 shows the Google activity data for U.S. states. The heterogeneity of experience stands out, with some states close to "normal" by the summer while others remain 30 to 40 percent below baseline. Interestingly, Washington DC stands out: it has the largest decline of any state at virtually all dates, with activity more than 50 percent below baseline throughout the summer. Recall the contrast with the unemployment data shown earlier in Figures 6 and 7. As the nation's capital, Washington DC is a special place: a large fraction of jobs are in the government sector and so therefore experienced small declines, while many employees are highly mobile, both nationally and internationally, resulting in large losses in Google activity. 
Figure 10: Google Activity for Key Global Cities

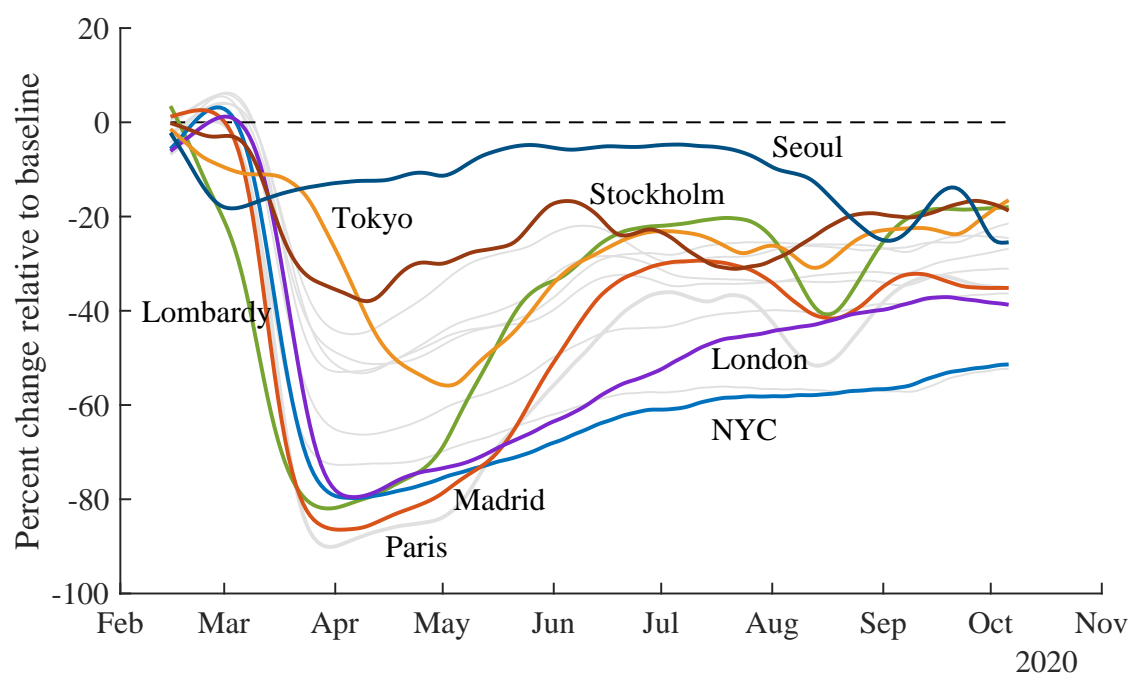

Note: Google activity is the equally-weighted average of the "retail and entertainment" and "workplace" categories. The data are smoothed with an HP filter with smoothing parameter 400.

Figure 11: Google Activity for Key U.S. States

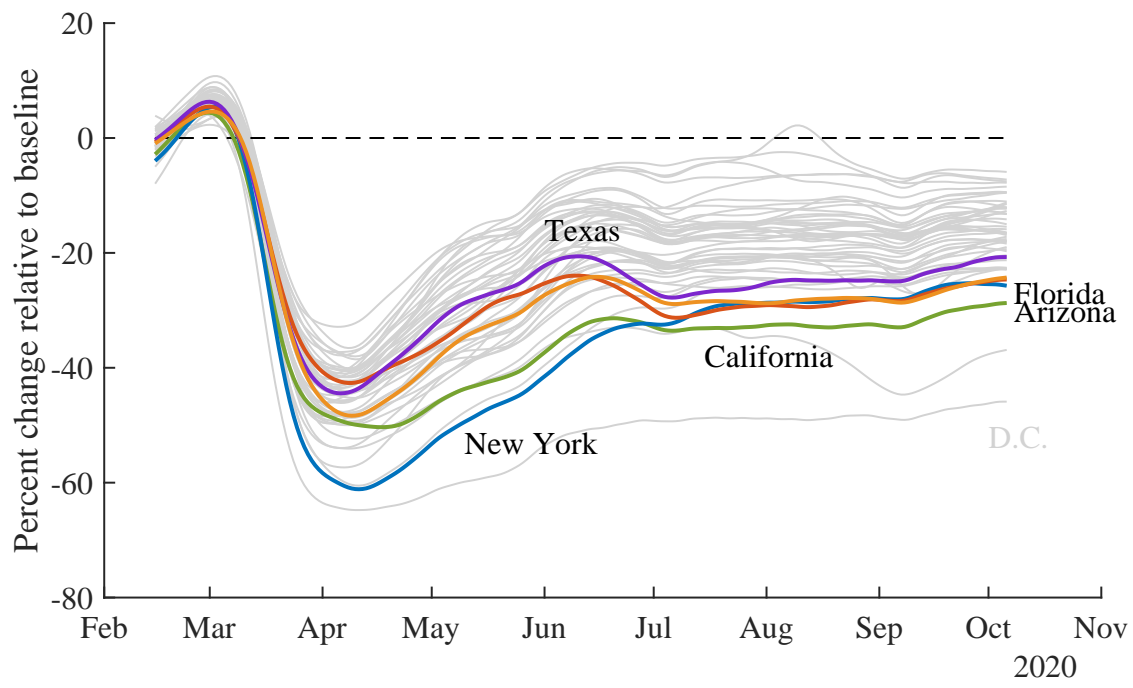

Note: Google activity is the equally-weighted average of the "retail and entertainment" and "workplace" categories. The data are smoothed with an HP filter with smoothing parameter 400. 
Figure 12: Google Activity for Key U.S. States and Countries

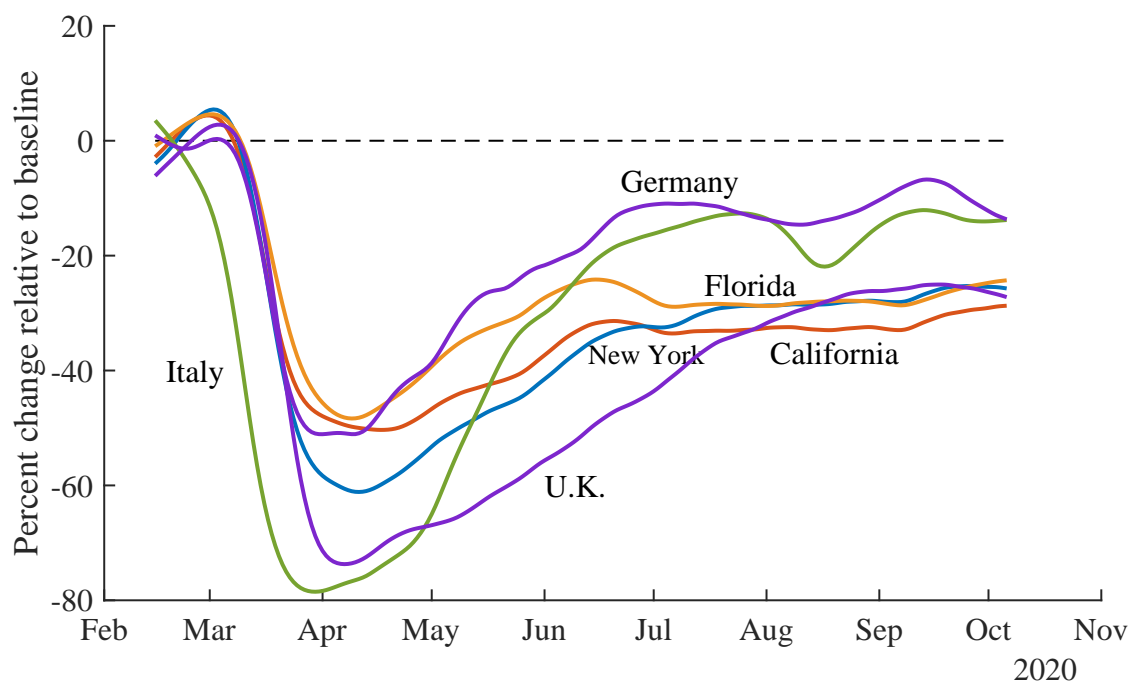

Note: Google activity is the equally-weighted average of the "retail and entertainment" and "workplace" categories. The data are smoothed with an HP filter with smoothing parameter 400.

Finally, Figure 12 combines some of the key states and countries into a single graph for ease of comparison. The declines in Google activity in Italy and the U.K. are substantially larger than the declines in New York state and California, while Germany stands out as having even milder declines in activity than Florida. While the U.K. was slower than Italy (and slower than Spain and Germany — see Figure 8) to shut down, it was as fast as New York and contracted economic activity more severely. New York state had much worse outcomes in terms of deaths (1700 versus 600 ), and this is true even if we compare New York City (2800) versus London (650) 


\subsection{Correlating Economic Activity and Google Mobility}

Figure 13: Cumulative Google Activity and Lost GDP

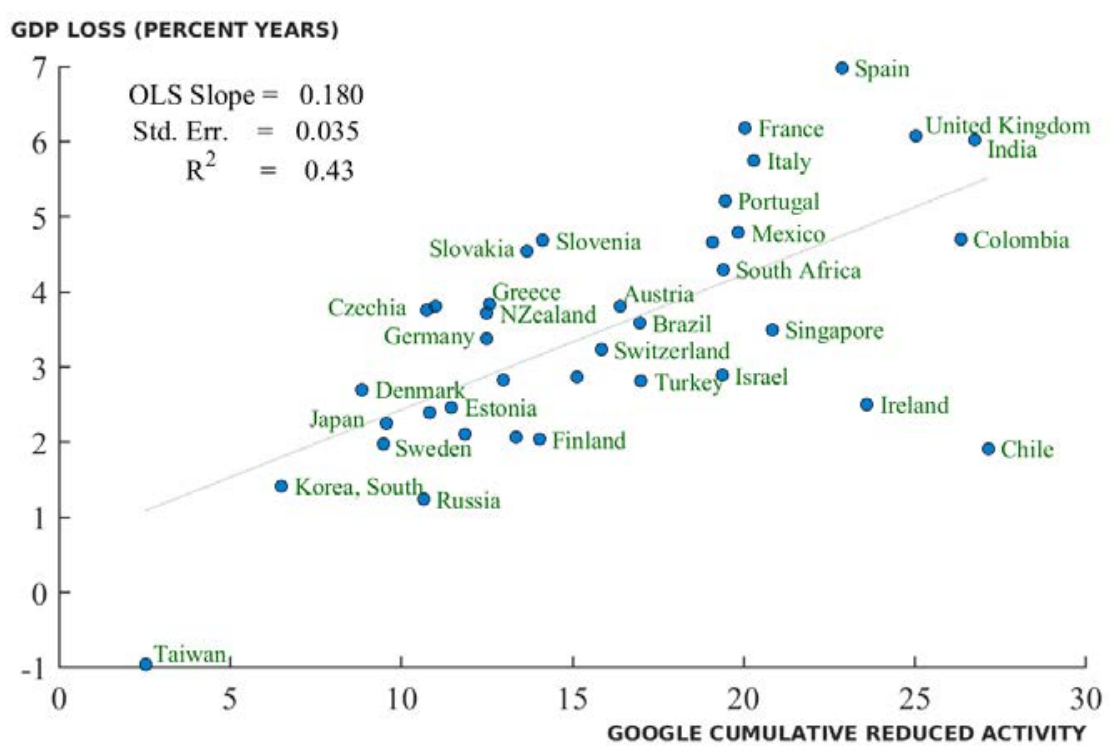

Note: "GDP Loss" reports the cumulative loss in GDP since the start of 2020 as a percent of annual GDP. "Google Cumulative Reduced Activity" measures the total amount of lost Google activity at an annual rate. The correlation in the graph is 0.65 .

Before showing the "tradeoff" graphs with the Google activity measure, we first demonstrate that this measure is correlated with the GDP loss and cumulative excess unemployment. The correlation with the GDP loss is shown in Figure 13. Here and in what follows, we add up the areas in the Google activity graphs shown above to get a cumulative loss in Google activity. In particular, "Google Cumulative Reduced Activity" measures the total amount of lost Google activity at an annual rate. A value of 20 indicates that, relative to baseline, it is as if activity at retail, entertainment, and workplace locations was reduced by 20 percent for an entire year. For example, a 40 percent reduction in activity each month for six months would deliver this value.

Figure 13 illustrates that the Google activity measure is a useful proxy for economic activity. The correlation between the loss in GDP and the cumulative reduction in activity is 0.65 (the square root of 0.43 ).

Figure 14 shows this same kind of evidence for U.S. states, only this time for cumulate excess unemployment. The correlation with Google activity is 0.50 if Washington 
Figure 14: Cumulative Google Activity and Cumulative Excess Unemployment

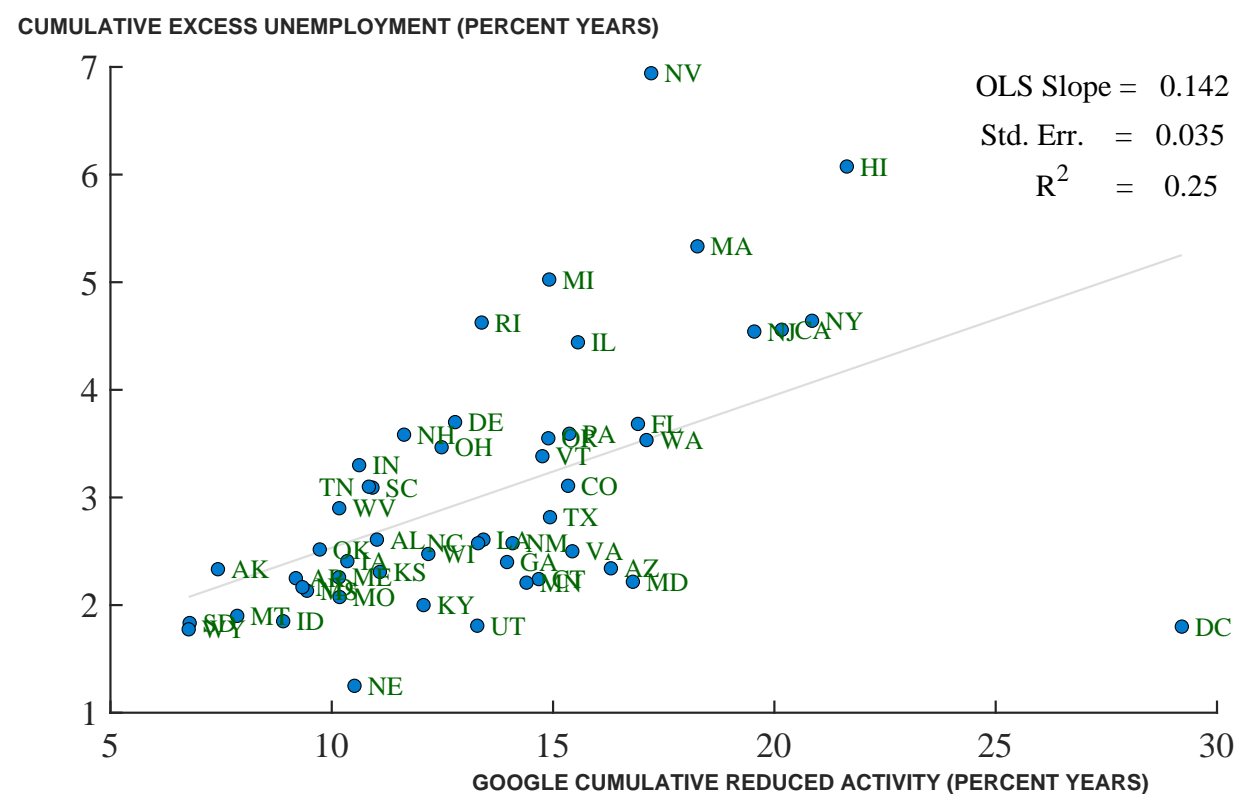

Note: The correlation is 0.50 ; it rises to 0.69 if Washington DC is dropped.

DC is included, but the "outlier" nature of the District of Columbia has already been mentioned. The correlation rises to 0.69 if this outlier is dropped. 
Figure 15: Covid Deaths (Latest) and Cumulative Google Activity (September)

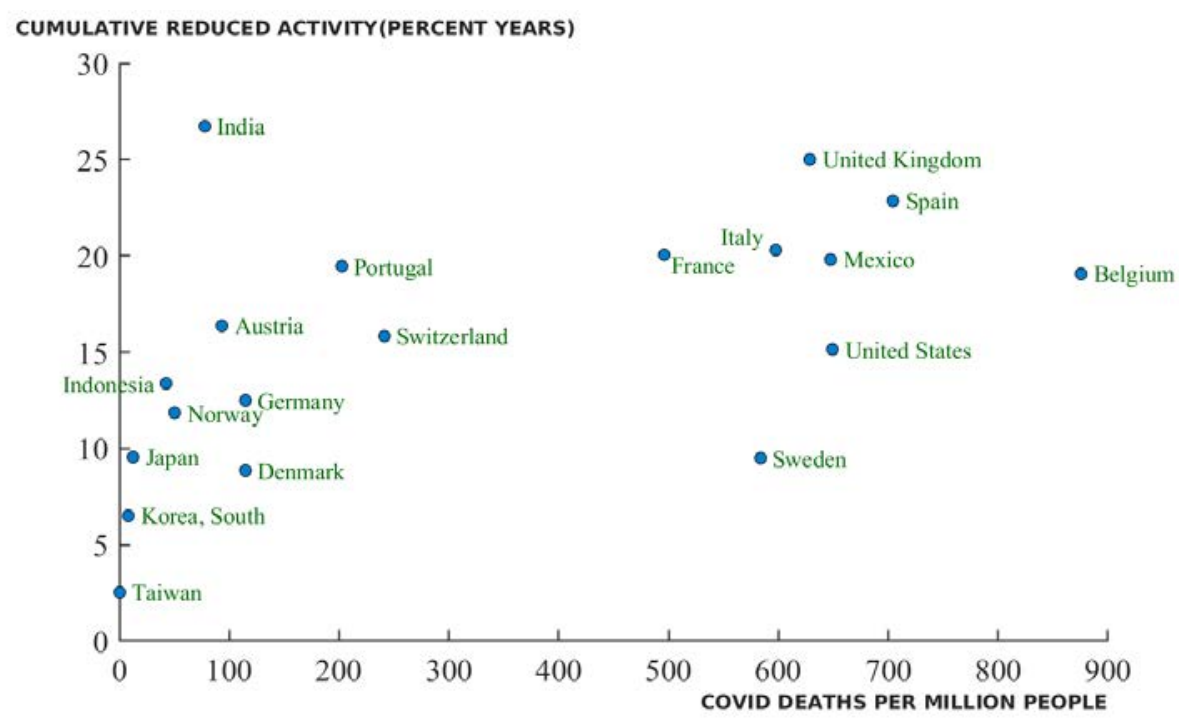

Note: Google activity is the equally-weighted average of the "retail and entertainment" and "workplace" categories. "Cumulative" refers to the fact that we add up the losses for every month since February 2020.

\subsection{Cumulative Results}

Countries. Figure 15 shows the cumulative lost activity according to the Google mobility data as of October 9 . The first thing to appreciate is that the graph looks very similar to the GDP loss graph in Figure 5. This is of course just another way of saying that the GDP data and Google data are highly correlated.

The key takeaways from this figure are therefore also similar. Belgium, the U.K., Spain, and Italy have both very high deaths and very large losses in macroeconomic activity. Taiwan, Korea, and Japan, as well as Denmark, Norway, and Germany are in the lower left of the graph, with good performance on both dimensions. Sweden stands out. It looks successful compared to countries like the U.K., Spain, and Italy, with similar deaths but much smaller losses in GDP. On the other hand, compared to Norway and Germany, Sweden looks much less successful, with similar losses in economic activity but far more deaths. The United States is a similar case in that it has fewer deaths and smaller losses in economic activity than the U.K., Spain, and Italy, but looks much worse than Norway and Germany. India stands out in the "northwest" quadrant of the graph, having large losses in economic activity with comparatively few deaths. The 
Figure 16: Global Cities: Covid Deaths and Cumulative Google Activity

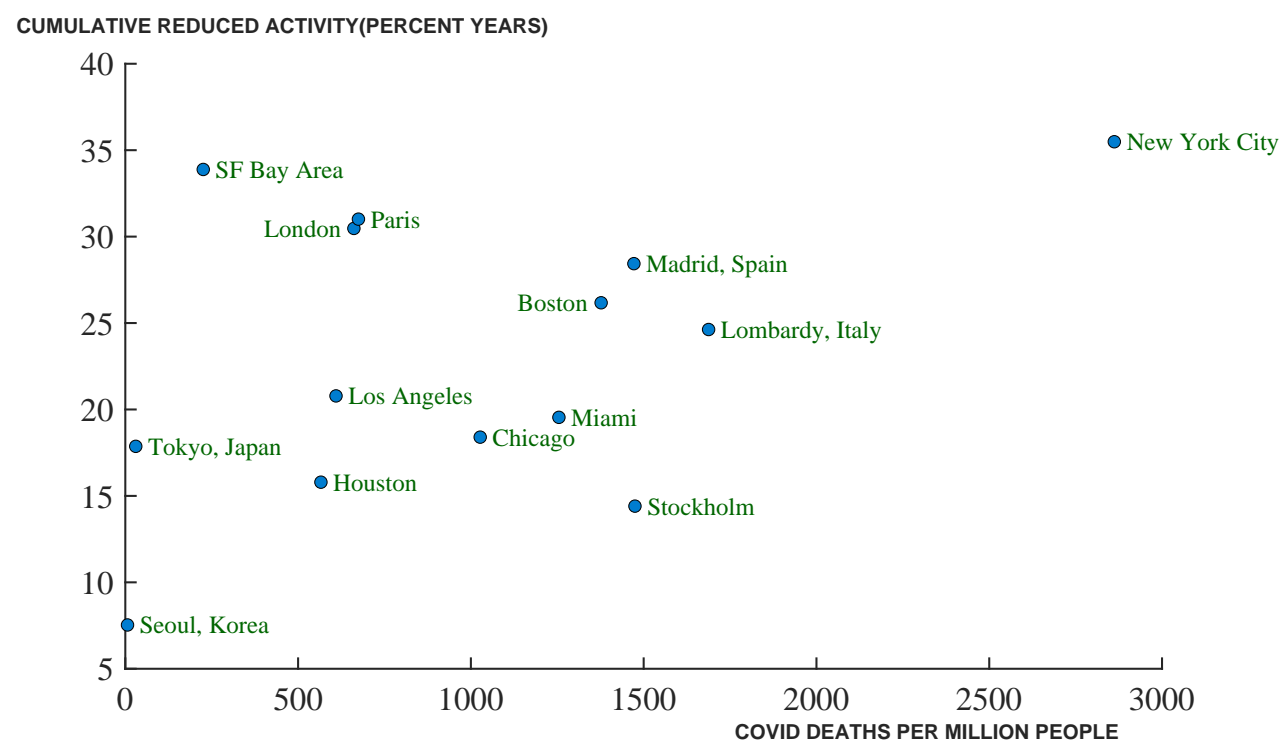

U.S. and India have the additional disadvantage — discussed more below — that their situations are still very much evolving.

Cities. Figure 16 shows one of advantages of the Google data by disaggregating to the city level for a collection of key cities around the world. Broadly speaking, we see the same types of outcomes for cities that we saw for countries and states with the earlier macroeconomic data. New York City has by far the highest death rate in the world at around 2800 per million people. Interestingly, it also has the largest cumulative economic loss, equivalent to around 35 percent of a year's activity.

The economic loss is only slightly larger than losses in other cities such as London, Paris, and San Francisco. These cities have far fewer deaths than New York City, however, at around 650 per million for London and Paris and just 220 for the San Francisco Bay Area.

Madrid, Boston, and Lombardy stand out the way Spain and Italy did before, with a high death rate and large economic losses. In contrast, Seoul and Tokyo are much like South Korea and Japan. Stockholm also plays the same role that Sweden did.

Finally, cities such as Los Angeles and Houston lie in the middle, with deaths somewhat similar to Paris and London, but with noticeably less cumulative loss in economic activity. 
Figure 17: U.S. States: Covid Deaths and Cumulative Google Activity

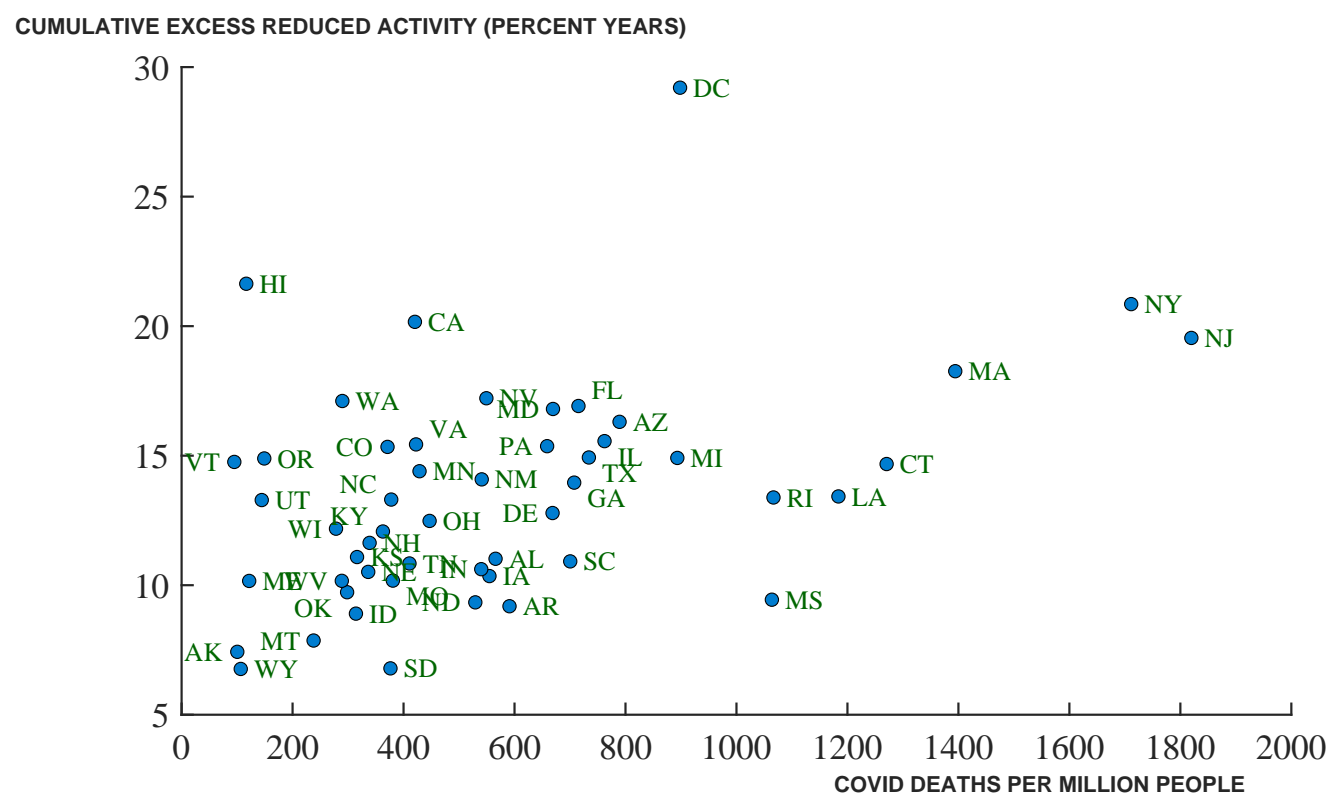

U.S. States. Figure 17 shows the Google activity data and deaths for U.S. states. Apart from Washington D.C. - where the large decline in activity contrasts with the small rise in the unemployment rate, as noted above - the pattern is quite similar to what we saw in the unemployment data back in Figure 7. 


\section{Dynamic Versions of the Trade-off Graphs}

We now take advantage of the high-frequency nature of both the Google activity data and the Covid data to examine the dynamic evolution of our outcomes. In what follows, we show our outcomes at the monthly frequency, from March through September. Each dot in the graph is a monthly observation, connected in order, and with the location name highlighted next to the most recent observation. After experimenting with different ways of showing these data, we focus on plots for the current (flow) Google activity measure instead of the cumulative loss in economic activity.

Figure 18: Monthly Evolution from March to September

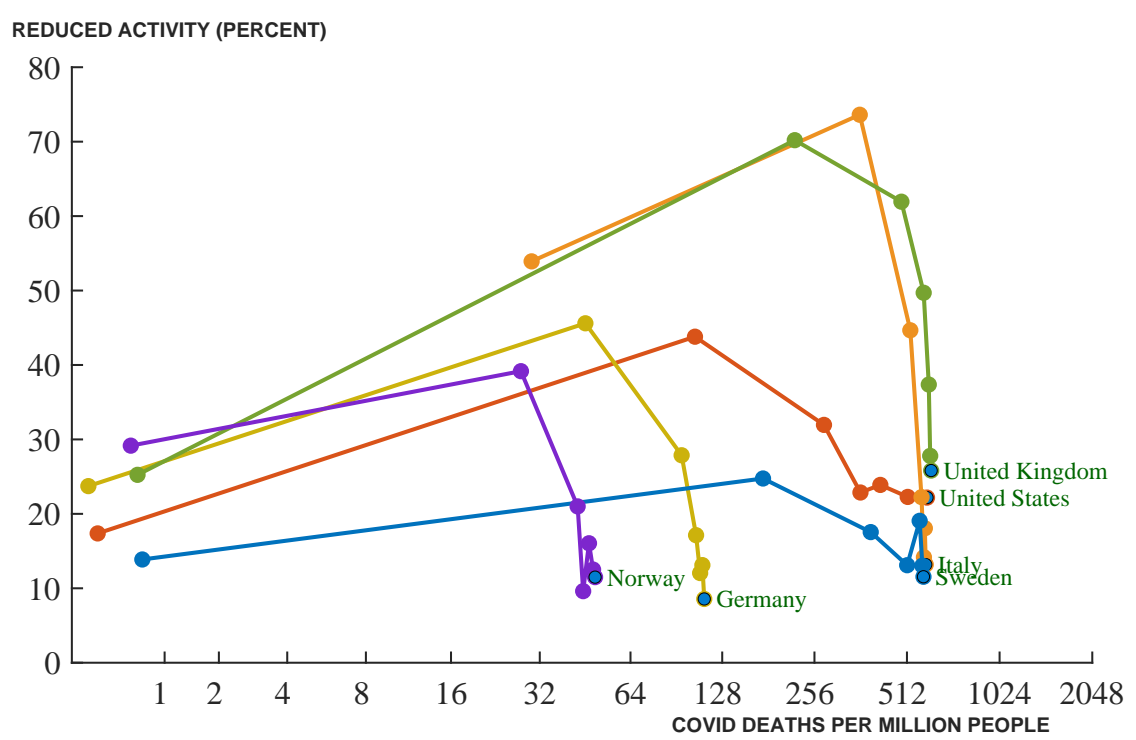

Note: The vertical axis is the current flow of Google activity, averaged for each month. The horizontal axis plots $\log (1+$ deaths $)$ where deaths are as of the 15th of each month.

Countries. Figure 18 shows the dynamics for the flow of Google activity for a small set of countries, focused on the U.S. and some key European economies. The general pattern is that between March and April, countries move sharply up and to the right, as Covid deaths explode and the economies severely restrict economic activity. After April, countries break in two directions. Italy, Germany, Norway, and the U.K. see their Covid deaths stabilize either by May or certainly by June, and economic activity starts to recover: the dynamics take the lines sharply downward. In Sweden and the United 
States, in contrast, the pandemic continues: deaths continue to increase and economic activity recovers much less; the movement is more to the right instead of straight down.

Figure 19 shows this same kind of graph for an additional dozen countries including Taiwan, South Korea, India, Japan, Mexico, France, and Spain. The same two types of experiences are seen among these additional countries. Most have a large sharp move up and to the right followed by a recovery in economic activity and a stabilization of deaths, illustrated by the vertical nature of the lines in the graph. In contrast, Mexico, India, and Indonesia experience a persistent move to the right as the pandemic continues and deaths have yet to stabilize.

Figure 19: Monthly Evolution from March to September

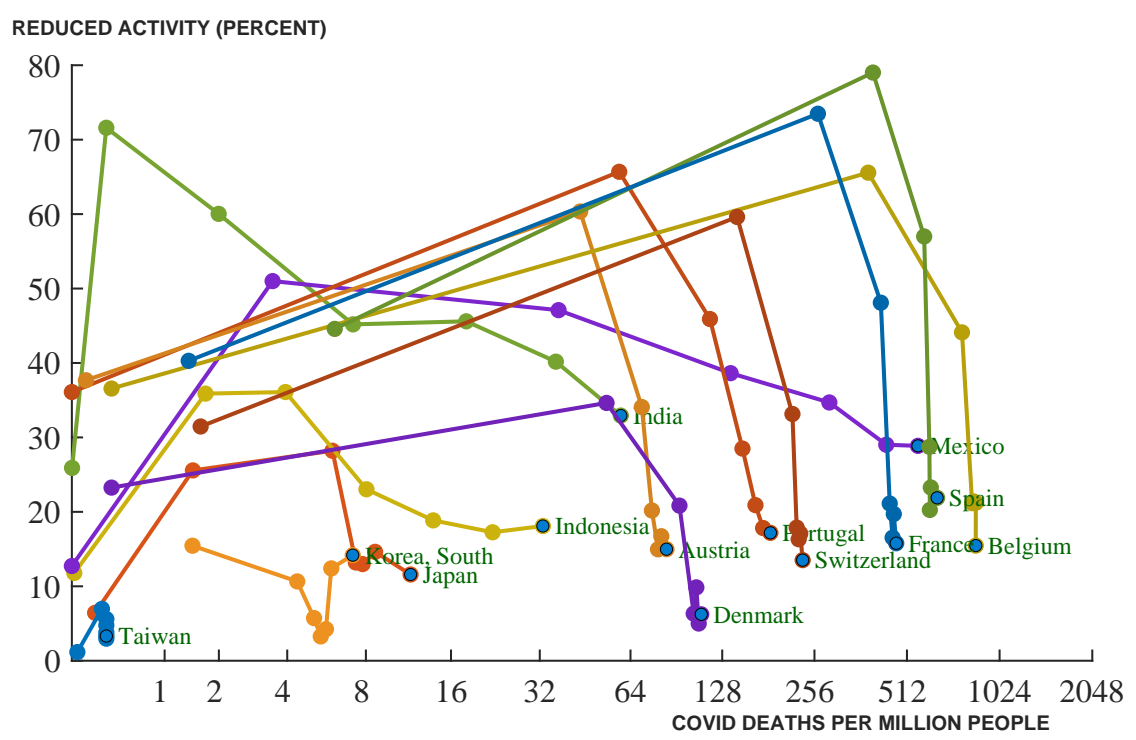

Note: See notes to Figure 18.

Global cities. Figure 20 shows similar dynamics for key cities around the world. New York City, Lombardy, Madrid, London, and Paris all move sharply up and to the right with the onset of the pandemic. By May, however, the stabilization of deaths and the gradual reopening of the economies is apparent in the vertical portion of the curve.

Stockholm is an interesting contrast in that Google activity declines by only about 20 to 30 percent for the entire spring, far less than in many other cities. On the other hand, the rightward move continues for longer, resulting in appreciably more deaths. 
Figure 20: Global Cities: Monthly Evolution from March to September

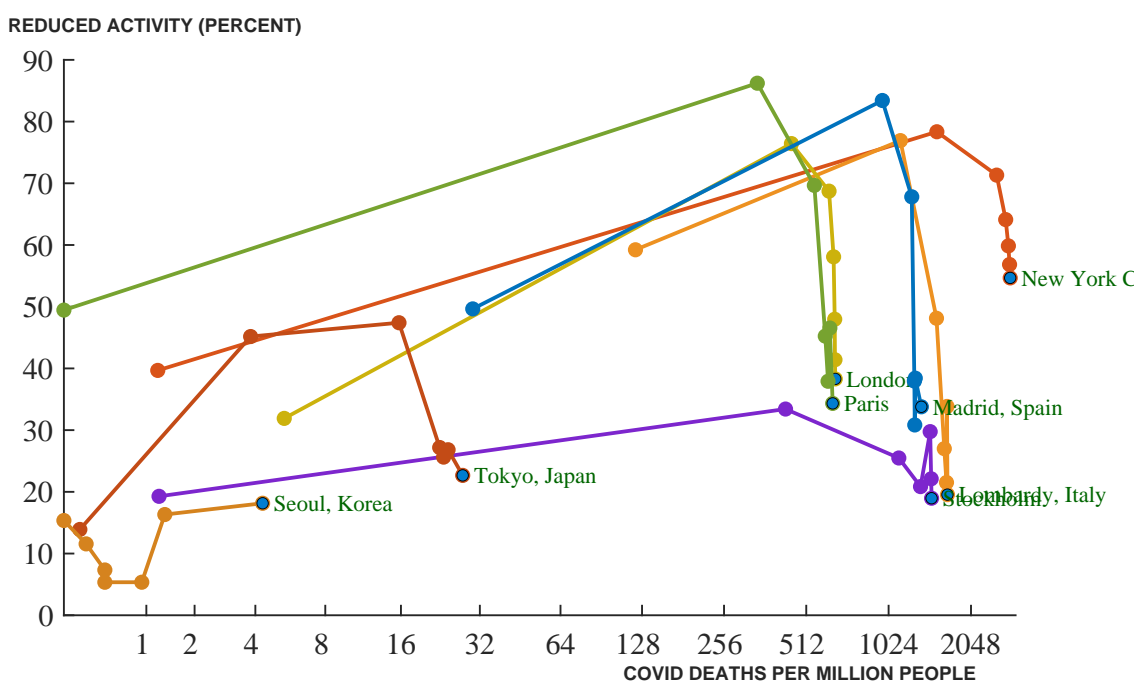

Note: See notes to Figure 18.

Finally, Tokyo and Seoul are interesting to compare. Tokyo had a much larger decline in economic activity peaking at around 45 percent in April and May. By comparison, Seoul saw reductions of 20 percent or less each month. While both cities end with enviably low deaths, the death rate in Seoul is around 4 per million versus around six times larger at 24 per million in Tokyo.

Figure 21 shows a similar graph for several other cities in the United States. Here the continued rightward moves in Houston, Miami, Los Angeles, and San Francisco are evidence that the pandemic is not yet under control.

U.S. states. The next two figures show the dynamics for U.S. states, confirming the two types of patterns we've seen in countries and cities. Figure 22 shows that in states like New York, New Jersey, Massachusetts, Michigan, and Pennsylvania, deaths have stabilized. By contrast, Figure 23 shows many states where this is not true. The continued rightward movement documents the continued rise in deaths from COVID-19. 
Figure 21: Global Cities: Monthly Evolution from March to September

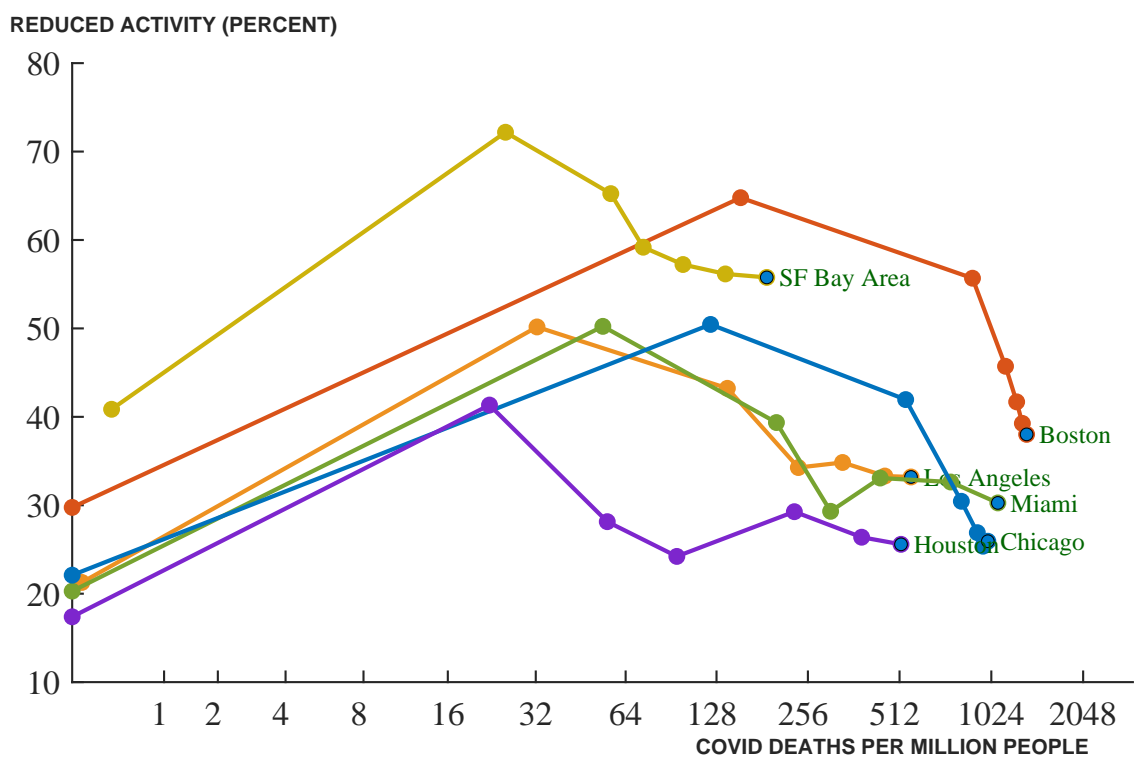

Note: See notes to Figure 18.

Figure 22: U.S. States: Monthly Evolution from March to September

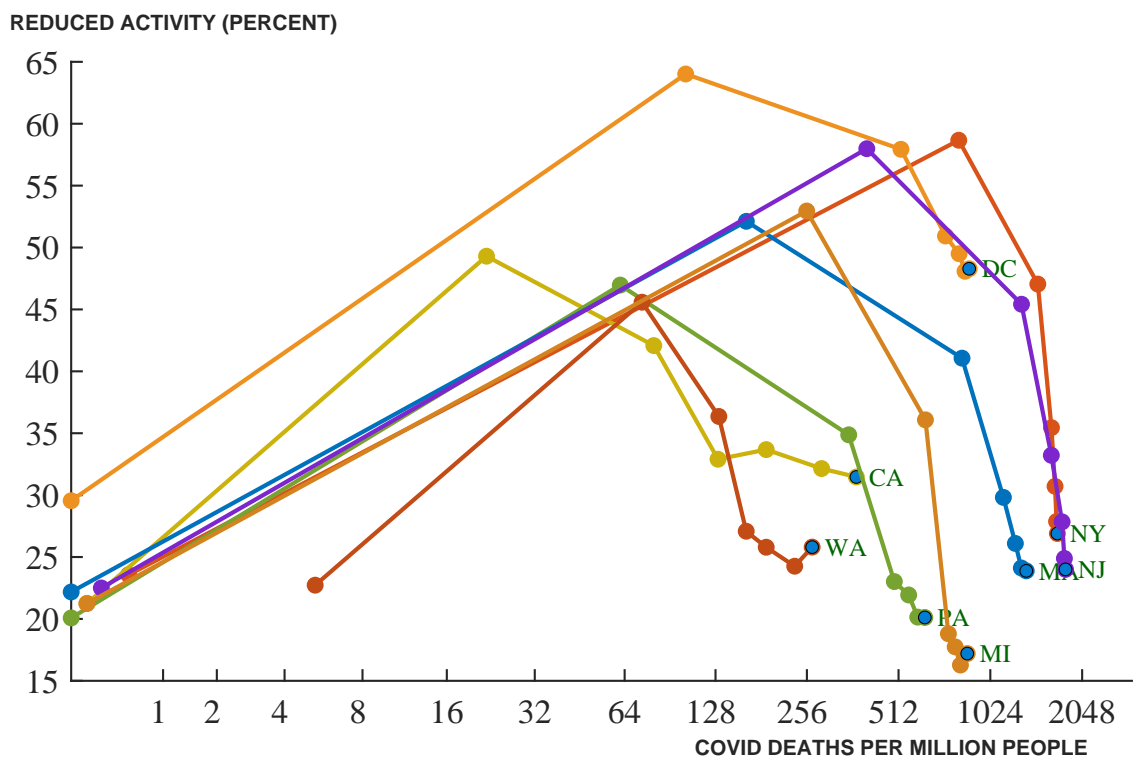

Note: See notes to Figure 18. 
Figure 23: U.S. States: Monthly Evolution from March to September

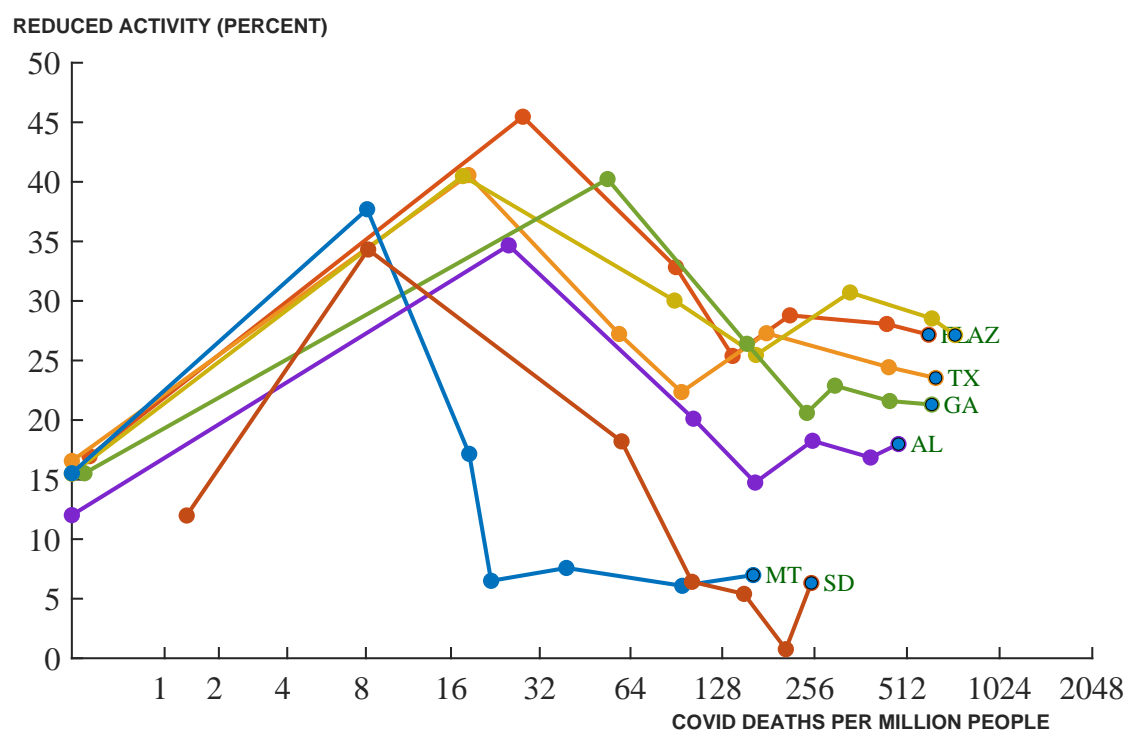

Note: See notes to Figure 18. 


\section{Conclusion}

We have combined data on GDP, unemployment, and Google's COVID-19 Community Mobility Reports with data on deaths from COVID-19 to study the pandemic's macroeconomic outcomes.

Our main finding is that most countries/regions/cities fall in either of two groups: large GDP losses and high fatality rates (New York City, Lombardy, United Kingdom,..) or low GDP losses and low fatality rates (Germany, Norway, Kentucky, ...). Only a few exceptions, mainly California and Sweden, depart from this pattern.

This correlation has a simple explanation at a mechanical level. Through some combination of government mandates and voluntary changes in behavior, those areas that suffered high mortality reduced economic activity dramatically to lower social contacts and slow down the pandemic's spread. In comparison, those locations that were able to control the virus from the beginning could maintain economic activity and suffer fewer deaths.

This observation suggests that controlling the epidemic is vital to mitigating GDP losses. It is easy to be sympathetic with this view, as it avoids the classical trade-offs in economics between alternative ends. With COVID-19, the evidence suggests that it is possible to be successful on both dimensions, minimizing deaths as well as other economic losses.

Nonetheless, it is challenging given our current data to gauge the extent to which a low death toll was the product of good luck versus good policy. Taiwan, South Korea, and Germany have been praised for their early and aggressive testing programs and intensive use of contact tracing, and several papers have highlighted the effectiveness of non-pharmaceutical interventions. But Taiwan and South Korea might have been hit by a less contagious form of the virus and might have benefited from prior experience with SARS and MERS. More of the circulation of SARS-CoV-2 in Germany might have occurred among younger cohorts than in other European countries. Further research will be required to separate the roles of luck from policy and to determine which policies were especially effective.

These arguments also work in reverse when we analyze the two main outliers in our data set: California and Sweden. California seems to have lost too much GDP given the severity of the health crisis it faced. Sweden could have reduced its mortality 
without too much GDP loss, at least as suggested by its Nordic neighbors' performance. But again, California was hit early by the first form of virus, perhaps less contagious. From the perspective of California's policymakers, the decisions taken ex-ante in March might be fully justified even if too tight ex-post. Sweden might have suffered from higher density in Stockholm, worse demographics, and other social differences with its neighbors.

Finally, we should notice that COVID-19 has policy spillovers, both in terms of health and economic outcomes. Had Italy controlled its epidemic earlier, France and Germany might have suffered a milder crisis. And if China had not undertaken draconian measures in Wuhan, South Korea might look very different today. Before rushing to judgment regarding the effect of different policies, these spillover effects must be analyzed in more detail. Regarding economic outcomes, a fall in global economic activity has dire consequences even for countries that have been able to control the virus. For example, Goldberg and Reed (2020) document that emerging market and developing economies have suffered from massive capital outflows and large price declines for certain commodities, especially oil and nonprecious metals.

Our conclusions are subject to a fundamental consideration. Health professionals in China started to suspect the presence of a new respiratory disease in the last week of December 2019. The first public message regarding the pandemic occurred on December 31, 2019, and was reported as a minor news item by a few Western media outlets. Only ten months have passed since that news.

Furthermore, the pandemic continues. Even in the best-case scenario in which effective vaccines and rapid tests become widely available by early 2021 , we still face, at the very least, several more months of the current situation. There are already some indications that an additional wave of the pandemic may crest in the autumn and winter.

All the graphs that we report may look quite different six months from now. By then, it may be much more apparent how much the divergence in outcomes is driven by luck and by policy. 


\section{References}

Acemoglu, Daron, Victor Chernozhukov, Iván Werning, and Michael D Whinston, "Optimal Targeted Lockdowns in a Multi-Group SIR Model,” Working Paper 27102, National Bureau of Economic Research May 2020.

Alon, Titan, Matthias Doepke, Jane Olmstead-Rumsey, and Michèle Tertilt, "The Impact of COVID-19 on Gender Equality," Working Paper 26947, National Bureau of Economic Research April 2020.

Álvarez, Fernando E., David Argente, and Francesco Lippi, "A Simple Planning Problem for COVID-19 Lockdown," Working Paper 26981, National Bureau of Economic Research April 2020.

Amuedo-Dorantes, Catalina, Neeraj Kaushal, and Ashley N. Muchow, "Is the Cure Worse than the Disease? County-Level Evidence from the COVID-19 Pandemic in the United States," Working Paper 27759, National Bureau of Economic Research August 2020.

Arnon, Alexander, John Ricco, and Kent Smetters, "Epidemiological and Economic Effects of Lockdown,” Working Paper, Penn Wharton Budget Model 2020.

Aruoba, S. Boragan, "Data Revisions Are Not Well Behaved," Journal of Money, Credit and Banking, 2008, 40 (2/3), 319-340.

Atkeson, Andrew, Karen Kopecky, and Tao Zha, "Four Stylized Facts about COVID-19," Working Paper 27719, National Bureau of Economic Research August 2020.

Aum, Sangmin, Sang Yoon (Tim) Lee, and Yongseok Shin, “COVID-19 Doesn't Need Lockdowns to Destroy Jobs: The Effect of Local Outbreaks in Korea," Working Paper 27264, National Bureau of Economic Research May 2020.

Baqaee, David and Emmanuel Farhi, "Nonlinear Production Networks with an Application to the Covid-19 Crisis,” Working Paper 27281, National Bureau of Economic Research May 2020.

_ and _ , "Supply and Demand in Disaggregated Keynesian Economies with an Application to the Covid-19 Crisis," Working Paper 27152, National Bureau of Economic Research May 2020.

_ , _ , Michael J Mina, and James H Stock, "Reopening Scenarios,” Working Paper 27244, National Bureau of Economic Research May 2020.

Born, Benjamin, Alexander Dietrich, and Gernot Müller, "The effectiveness of lockdowns: Learning from the Swedish experience," Discussion Papers 14744, CEPR Discussion Paper August 2020. 
Cajner, Tomaz, Leland D Crane, Ryan A Decker, John Grigsby, Adrian Hamins-Puertolas, Erik Hurst, Christopher Kurz, and Ahu Yildirmaz, "The U.S. Labor Market during the Beginning of the Pandemic Recession,” Working Paper 27159, National Bureau of Economic Research May 2020.

Chen, Sophia, Deniz O Igan, Nicola Pierri, and Andrea F Presbitero, "Tracking the Economic Impact of COVID-19 and Mitigation Policies in Europe and the United States," IMF Working Papers 20/125, International Monetary Fund July 2020.

Chetty, Raj, John N Friedman, Nathaniel Hendren, Michael Stepner, and The Opportunity Insights Team, "How Did COVID-19 and Stabilization Policies Affect Spending and Employment? A New Real-Time Economic Tracker Based on Private Sector Data," Working Paper 27431, National Bureau of Economic Research June 2020.

Cho, Sang-Wook (Stanley), "Quantifying the impact of non-pharmaceutical interventions during the COVID-19 outbreak - The case of Sweden," The Econometrics Journal, 082020.

Ciminelli, Gabriele and Sílvia Garcia-Mandicó, "COVID-19 in Italy: An analysis of death registry data, part II,” 2020. https://voxeu.org/article/covid-19-italy-analysis-death-registry-datapart-ii.

Couture, Victor, Jonathan I Dingel, Allison E Green, Jessie Handbury, and Kevin R Williams, "Measuring Movement and Social Contact with Smartphone Data: A Real-Time Application to COVID-19," Working Paper 27560, National Bureau of Economic Research July 2020.

Eichenbaum, Martin S, Sergio Rebelo, and Mathias Trabandt, "The Macroeconomics of Epidemics," Working Paper 26882, National Bureau of Economic Research March 2020.

Fang, Hanming, Long Wang, and Yang Yang, "Human Mobility Restrictions and the Spread of the Novel Coronavirus (2019-nCoV) in China," Working Paper 26906, National Bureau of Economic Research March 2020.

Farboodi, Maryam, Gregor Jarosch, and Robert Shimer, "Internal and External Effects of Social Distancing in a Pandemic," Technical Report 2020-47 2020. University of Chicago, Becker Friedman Institute for Economics Working Paper.

Forsythe, Eliza, Lisa B. Kahn, Fabian Lange, and David Wiczer, "Labor demand in the time of COVID-19: Evidence from vacancy postings and UI claims," Journal of Public Economics, 2020, 189, 104238. 
Glover, Andrew, Jonathan Heathcote, Dirk Krueger, and José-Víctor Ríos-Rull, "Health versus Wealth: On the Distributional Effects of Controlling a Pandemic," Working Paper 27046, National Bureau of Economic Research April 2020.

Goldberg, Pinelopi K. and Tristan Reed, "The effects of the coronavirus pandemic in emerging market and developing economies An optimistic preliminary account," Brooking Papers on Economic Activity, 06 2020, 1.

Google, “COVID-19 Community Mobility Reports," 2020. Downloaded on October 9 from https: //www.google.com/covid19/mobility/.

Goolsbee, Austan and Chad Syverson, "Fear, Lockdown, and Diversion: Comparing Drivers of Pandemic Economic Decline 2020," Working Paper 27432, National Bureau of Economic Research June 2020.

Gottlieb, C., J. Grobovsek, M. Poschke, and M. Saltiel, "Lockdown Accounting," Covid Economics, 2020, 31, 103-130.

Grubaugh, N.D., W.P. Hanage, and A.L. Rasmussen, "Making Sense of Mutation: What D614G Means for the COVID-19 Pandemic Remains Unclear," Cell, 2020, 182 (4), 794-795.

Gupta, Sumedha, Thuy D Nguyen, Felipe Lozano Rojas, Shyam Raman, Byungkyu Lee, Ana Bento, Kosali I Simon, and Coady Wing, "Tracking Public and Private Responses to the COVID-19 Epidemic: Evidence from State and Local Government Actions," Working Paper 27027, National Bureau of Economic Research April 2020.

$\mathrm{Hu}$, Jie, Chang-Long He, Qing-Zhu Gao, Gui-Ji Zhang, Xiao-Xia Cao, Quan-Xin Long, Hai-Jun Deng, Lu-Yi Huang, Juan Chen, Kai Wang, Ni Tang, and Ai-Long Huang, "D614G mutation of SARS-CoV-2 spike protein enhances viral infectivity," Technical Report, Key Laboratory of Molecular Biology for Infectious Diseases 2020.

Johns Hopkins University CSSE, “2019 Novel Coronavirus COVID-19 (2019-nCoV) Data Repository," 2020. Center for Systems Science and Engineering.

Juranek, Steffen, Jörg Paetzold, Hannes Winner, and Floris Zoutman, "Labor Market Effects of COVID-19 in Sweden and Its Neighbors: Evidence from Novel Administrative Data," CESifo Working Paper Series 8473, CESifo 2020.

Karaivanov, Alexander, Shih En Lu, Hitoshi Shigeoka, Cong Chen, and Stephanie Pamplona, "Face Masks, Public Policies and Slowing the Spread of COVID-19: Evidence from Canada," Working Paper 27891, National Bureau of Economic Research October 2020. 
Korber, B., S. Gnanakaran, WM Fischer, H Yoon, J Theiler, W Abfalterer, N Hengartner, EE Giorgi, T Bhattacharya, B Foley, KM Hastie, MD Parker, DG Partridge, CM Evans, TM Freeman, TI de Silva, C McDanal, Perez LG, H Tang, A Moon-Walker, SP Whelan, CC LaBranche, EO Saphire, and DC Montefiori, "Tracking changes in SARS-CoV-2 Spike: evidence that D614G increases infectivity of the COVID-19 virus," Cell, 2020, 182 (4), 812-827.

Mitze, Timo, Reinhold Kosfeld, Johannes Rode, and Klaus Wälde, "Face Masks Considerably Reduce COVID-19 Cases in Germany: A Synthetic Control Method Approach,” IZA Discussion Papers 13319, Institute of Labor Economics (IZA) June 2020.

Ng, Robert H. Brook C. Jason Wang Chun Y., "Response to COVID-19 in Taiwan: Big Data Analytics, New Technology, and Proactive Testing,” JAMA, 04 2020, 323 (14), 1341-1342.

OECD, “Quarterly GDP (indicator),” 2020.

Ozono, Seiya, Yanzhao Zhang, Hirotaka Ode, Tan Toong Seng, Kazuo Imai, Kazuyasu Miyoshi, Satoshi Kishigami, Takamasa Ueno, Yasumasa Iwatani, Tadaki Suzuki, and Kenzo Tokunaga, "Naturally mutated spike proteins of SARS-CoV-2 variants show differential levels of cell entry," Technical Report, National Institute of Infectious Diseases 2020.

Stock, James H, "Data Gaps and the Policy Response to the Novel Coronavirus," Working Paper 26902, National Bureau of Economic Research March 2020.

Watanabe, Tsutomu and Tomoyoshi Yabu, "Japan's voluntary lockdown," Covid Economics, $2020,46,1-31$.

Zhang, Lizhou, Cody B Jackson, Huihui Mou, Amrita Ojha, Erumbi S Rangarajan, Tina Izard, Michael Farzan, and Hyeryun Choe, "The D614G mutation in the SARS-CoV-2 spike protein reduces S1 shedding and increases infectivity," Technical Report, The Scripps Research Institute 2020. 


\section{A. Data Sources}

Our GDP data comes mainly from the OECD (2020). We look at quarterly GDP, total, in percentage change with respect to the previous period. We add a few observations, such as Taiwan, not covered by the OECD.

Our death data comes from Johns Hopkins University CSSE (2020). We must remember, nevertheless, that data about deaths are subject to undercount and interpretation.

Regarding undercounting, and especially during the start of the epidemic, not all patients that died were tested for COVID-19. This was particularly true in Italy and Spain, where deaths were initially heavily concentrated in nursing homes, whose management became overwhelmed with the health crisis. Regarding interpretation, COVID19 is particularly lethal for older individuals with comorbidities. Imagine the case of a patient with terminal cancer that dies while infected with COVID-19. Should we count this as a COVID-19 death?

However, undercounting is likely to be of an order of magnitude more important than interpretation discrepancies. Several countries have centralized vital record systems that track all death certificates issued. Since these certificates are important for basic administrative procedures, compliance is close to universal. We can then use the total number of deaths observed in 2020 and subtract a forecast of deaths for 2020, given deaths in past years (and controlling for aging, weather, etc.) to obtain a measure of excess deaths.

The differences between death data from Johns Hopkins University CSSE (2020) and excess deaths can be considerable. Consider the case of Spain. ${ }^{7}$ Excess deaths between March 13 and October 7 according to the national mortality registry were 44,493, while the Johns Hopkins University CSSE (2020) deaths for the same period were 32,429, a difference of 37.2 percent. $^{8}$

At the same time, excess deaths have their own interpretation problems. First, if COVID-19 caused the deaths of many older individuals that were forecast to die in a

\footnotetext{
${ }^{7}$ See https://momo.isciii.es/public/momo/dashboard/momo_dashboard.html for details.

${ }^{8} \mathrm{March} 13$ was the first day total deaths were outside the 99 percent confidence interval of the forecast that used historical data, weather, and demographics. October 7 was the last day, so far, where total deaths were outside that confidence interval. Also, notice that the national mortality registry only reports data from electronic death certificates, which are issued by the local offices that cover around $93 \%$ of the total population. Thus excess deaths are likely to be around 48,000 .
} 
few months, a higher excess death in March will be compensated by an negative excess death, let's say, in November, masking the true COVID-19-related deaths in that month. Conversely, low deaths in previous years (such as mild flu season in 2019) might have implied a high mortality in 2020 even in the absence of the epidemic.

Second, the lockdowns also affected other death causes, both lowering them (fewer traffic and work accidents) and increasing them (fewer medical procedures undertaken, worsening physical and mental health triggered by the lockdowns and the economic crisis).

While we do not believe that Figure 5 would dramatically change once researchers have more accurate counts of COVID-19 deaths, this is an additional aspect where caution is necessary. 